\title{
Closed-Loop, Cervical, Epidural Stimulation Elicits Respiratory Neuroplasticity after Spinal Cord Injury in Freely Behaving Rats
}

\author{
Ian G. Malone, ${ }^{1,2}$ Mia N. Kelly, ${ }^{2,3}$ Rachel L. Nosacka, ${ }^{4}$ Marissa A. Nash,${ }^{4}$ Sijia Yue, ${ }^{5}$ Wei Xue, \\ Kevin J. Otto, ${ }^{1,2,6,7,8,9,10}$ and $\mathbb{C}^{-}$Erica A. Dale ${ }^{2,4,6}$
}

\section{https://doi.org/10.1523/ENEURO.0426-21.2021}

\begin{abstract}
${ }^{1}$ Department of Electrical and Computer Engineering, University of Florida, Gainesville, FL 32611, ${ }^{2}$ Breathing Research and Therapeutics Center, University of Florida, Gainesville, FL $32611,{ }^{3}$ Department of Physical Therapy, University of Florida, Gainesville, FL 32611, ${ }^{4}$ Department of Physiology and Functional Genomics, University of Florida, Gainesville, FL 32611, ${ }^{5}$ Department of Biostatistics, University of Florida, Gainesville, FL 32611, ${ }^{6}$ McKnight Brain Institute, University of Florida, Gainesville, FL 32611, ${ }^{7} \mathrm{~J}$. Crayton Pruitt Family Department of Biomedical Engineering, University of Florida, Gainesville, FL $32611,{ }^{8}$ Department of Materials Science and Engineering, University of Florida, Gainesville, FL 32611, ${ }^{9}$ Department of Neurology, University of Florida, Gainesville, FL 32611, and ${ }^{10}$ Department of Neuroscience, University of Florida, Gainesville, FL 32611
\end{abstract}

\begin{abstract}
Over half of all spinal cord injuries (SCls) are cervical, which can lead to paralysis and respiratory compromise, causing significant morbidity and mortality. Effective treatments to restore breathing after severe upper cervical injury are lacking; thus, it is imperative to develop therapies to address this. Epidural stimulation has successfully restored motor function after $\mathrm{SCl}$ for stepping, standing, reaching, grasping, and postural control. We hypothesized that closed-loop stimulation triggered via healthy hemidiaphragm EMG activity has the potential to elicit functional neuroplasticity in spinal respiratory pathways after cervical $\mathrm{SCI}(\mathrm{cSCl})$. To test this, we delivered closed-loop, electrical, epidural stimulation (CLES) at the level of the phrenic motor nucleus (C4) for $3 \mathrm{~d}$ after $\mathrm{C} 2$ hemisection (C2HS) in freely behaving rats. A $2 \times 2$ Latin Square experimental design incorporated two treatments, C2HS injury and CLES therapy resulting in four groups of adult, female Sprague Dawley rats: C2HS + CLES $(n=8)$, C2HS $(n=6)$, intact + CLES $(n=6)$, intact $(n=6)$. In stimulated groups, CLES was delivered for $12-20 \mathrm{~h} / \mathrm{d}$ for $3 \mathrm{~d}$. After C2HS, $3 \mathrm{~d}$ of CLES robustly facilitated the slope of stimulus-response curves of ipsilesional spinal motor evoked potentials (sMEPs) versus nonstimulated controls. To our knowledge, this is the first demonstration of CLES eliciting respiratory neuroplasticity after $\mathrm{C} 2 \mathrm{HS}$ in freely behaving animals. These findings suggest CLES as a promising future therapy to address respiratory deficiency associated with $\mathrm{cSCl}$.
\end{abstract}

Key words: cervical spinal cord injury; diaphragm EMG; epidural stimulation; respiratory neuroplasticity; respiratory rehabilitation; spinal motor evoked potentials

\section{Significance Statement}

Every year, globally, 250,000-500,000 people sustain a spinal cord injury (SCI). Over half of these injuries occur in the upper cervical spinal cord, disrupting bulbospinal pathways to cervical respiratory neurons, which impairs breathing ability. This diminished respiratory function is the leading cause of death among spinal cord injured patients. We adapted a method, which partially restores walking in paralyzed humans, to electrically stimulate the cervical spinal cord below the level of injury concurrent with breathing rhythm. We hypothesize this cervical-spinal electrical stimulation induces spinal respiratory plasticity (i.e., promotes lasting beneficial changes to the spinal network responsible for respiration). Our findings support this hypothesis, establishing this method as a promising potential therapy to ameliorate respiratory complications after SCl. 


\section{Introduction}

Over half of the annual 17,000 new spinal cord injury (SCI) cases in the United States occur at the cervical level (McDonald and Sadowsky, 2002; Vinit et al., 2006; National Spinal Cord Injury Statistical Center, 2020), which can damage bulbospinal projections and disrupt breathing ability (Fuller et al., 2006; Vinit et al., 2006). Respiratory insufficiency remains the leading cause of morbidity and mortality following cervical $\mathrm{SCl}$ (cSCl), necessitating the development of therapies to restore respiratory function (Garshick et al., 2005; Waddimba et al., 2009; Krause et al., 2016; Hall et al., 2019). Diaphragm pacing and phrenic nerve stimulation are promising (Carter et al., 1987; DiMarco, 2005; Brown et al., 2006; Romero et al., 2012), and recent reports demonstrate that spinal motor circuits may be activated via intraspinal (Sunshine et al., 2018), epidural (DiMarco et al., 2006, 2020; Kowalski et al., 2013; GonzalezRothi et al., 2017; Bezdudnaya et al., 2018), or temporal interference (Sunshine et al., 2021) stimulation, with open or closed-loop protocols (McPherson et al., 2015; Wagner et al., 2018). While these approaches show potential, many methods, unfortunately, require continuous stimulation and device dependence. Thus, it is imperative to develop rehabilitative strategies to reinstate sufficient and persistent breathing ability for meaningful improvements in the quality and duration of life after $\mathrm{CSCl}$.

Epidural stimulation has remarkable potential to improve volitional sensorimotor and autonomic responses, even in cases of clinically complete SCI (DiMarco, 2001; DiMarco et al., 2006; De Vries et al., 2007; Ardell et al., 2009, 2014; Edgerton and Harkema, 2011; Edgerton and Roy, 2012; Tator et al., 2012; Angeli et al., 2014; Duru et al., 2015). Most ( 65\%) SCls have spared axonal projections traversing the injury site (Bunge et al., 1997). Much of the success of epidural stimulation in the lumbosacral spinal cord has been attributed, in part, to these inputs

Received October 11, 2021; accepted December 24, 2021; First published January 20, 2022.

The authors declare no competing financial interests.

Author contributions: M.N.K. and E.A.D. designed research; I.G.M., M.N.K., R.L.N., M.A.N., and E.A.D. performed research; K.J.O. and E.A.D. contributed unpublished reagents/analytic tools; I.G.M., R.L.N., M.A.N., S.Y., W.X., K.J.O., and E.A.D. analyzed data; I.G.M., M.N.K., R.L.N., M.A.N., and E.A.D. wrote the paper.

This work was supported by the Craig H. Neilsen Foundation; The McKnight Brain Institute and University of Florida Brain and Spinal Cord Injury Research Trust Funds; the National Institutes of Health (NIH) Grant T32 HL134621 Breathing Research and Therapeutics Training Program, HL147554; the NIH Grant U01 NS099700; and University of Florida's University Scholars Program. Acknowledgements: We thank all members of the University of Florida's Dale Lab, NeuroProstheses Research Lab, and Mitchell Lab for their technical guidance; Dr. Raphael Perim, Dr. Kaitlynn Olczak, and Dr. Yasin Seven for their technical support, assistance, and mentorship; Larry Shupe and Dr. Chet Moritz and Dr. Eberhard Fetz for providing the Neurochip3 hardware and assisting with troubleshooting; and Dr. Jennifer Bizon, Dr. Jada Lewis, Dr. Peter Sayeski, Dr. David Fuller, Dr. Gordon Mitchell, Dr. Charlie Wood, and Dr. Stephen Sugrue for their support and guidance.

Correspondence should be addressed to Erica A. Dale at ericadale@ufl.edu. https://doi.org/10.1523/ENEURO.0426-21.2021 Copyright (c) 2022 Malone et al.

This is an open-access article distributed under the terms of the Creative Commons Attribution 4.0 International license, which permits unrestricted use, distribution and reproduction in any medium provided that the original work is properly attributed.
(Dimitrijevic et al., 1984; Sherwood et al., 1992, 1996; Edgerton et al., 2004; McKay et al., 2004; Rejc and Angeli, 2019). We predict that post-cSCl therapies targeting the cervical spinal cord can also benefit from spared fibers. However, rather than applying epidural stimulation techniques developed for the locomotor circuitry, factors specific to respiratory motor circuitry and the cervical spinal cord must be considered. For example, stimulation targeting locomotor networks likely relies on activation of an intraspinal circuit of pattern-generating neurons (Côté et al., 2018). The rhythm generators for breathing, however, lie within the ventral respiratory column of the brainstem (Smith et al., 1991), several segments rostral to the motor pools that they innervate and thereby are preserved after injury. Endogenous signals from intact rhythm generators provide the unique opportunity to harness activity-dependent mechanisms of neuroplasticity by stimulating respiratory motor pools in phase with a recorded rhythm (for review, see Malone et al., 2021). We predict using the breathing signal from intact components to time epidural stimulation in a closed-loop manner could be advantageous over open-loop paradigms (i.e., unpaired from respiratory rhythm), since (1) spinal respiratory circuits may be stimulated in a fatigue-resistant fashion; (2) stimulation will be endogenously adjusted to native respiratory load; and (3) the respiratory circuitry is highly plastic and could be "trained" via closed-loop reinforcement (e.g., Hebbian, activity-dependent plasticity).

To accomplish this, we developed a closed-loop epidural stimulation (CLES) paradigm using endogenous respiratory output to trigger CLES of the cervical spinal cord after CSCl (Fig. 1). Here, rats received a spinal hemisection at $\mathrm{C} 2(\mathrm{C} 2 \mathrm{HS})$ to ablate function in the ipsilesional hemidiaphragm. Subsequently, rats received $3 \mathrm{~d}$ of chronic, submotor threshold cervical CLES triggered from the functional, contralesional diaphragm EMG. Each day, for $4 \mathrm{~d}$ after termination of the electrical stimulation, we measured changes in spinal motor evoked potentials (sMEPs) to test the hypothesis that chronic CLES elicits spinal respiratory neuroplasticity (plasticity is a change in a neural control system based on prior experience; Mitchell and Johnson, 2003) and, therefore, could present a means of restoring independent breathing after $\mathrm{CSCl}$.

\section{Materials and Methods}

\section{Animals}

Experiments were performed on three- to five-monthold female Sprague Dawley rats (Envigo) weighing 250$300 \mathrm{~g}$. Rats were housed one-per-cage during experimentation, provided with food and water ad libitum, and maintained under a 12/12 h light/dark cycle. All experimental protocols were performed under the approval and guidance of the Institutional Animal Care and Use Committee at the University of Florida and conformed to policies found within the National Institutes of Health Guide for the Care and Use of Laboratory Animals.

\section{Experimental design and statistical analysis}

Female Sprague Dawley rats were split into four groups: (1) rats with a $\mathrm{C} 2 \mathrm{HS} \mathrm{SCl}$ that received CLES therapy, 
A

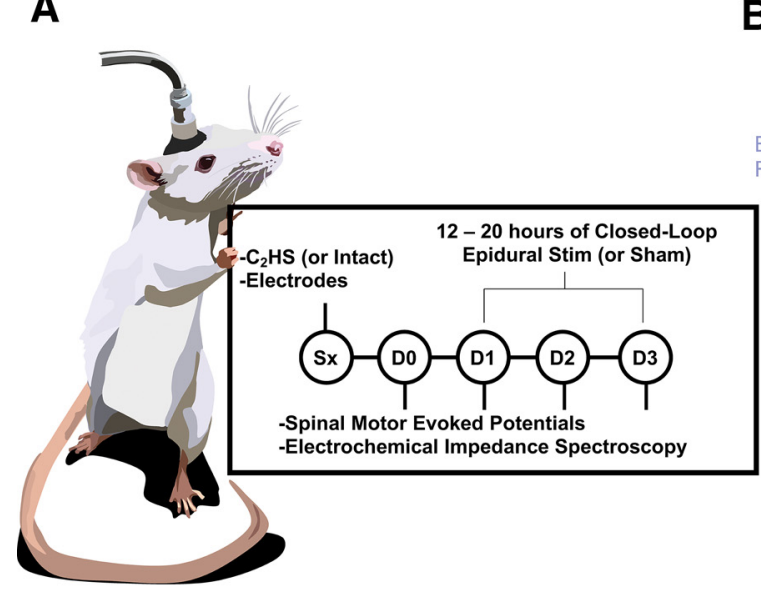

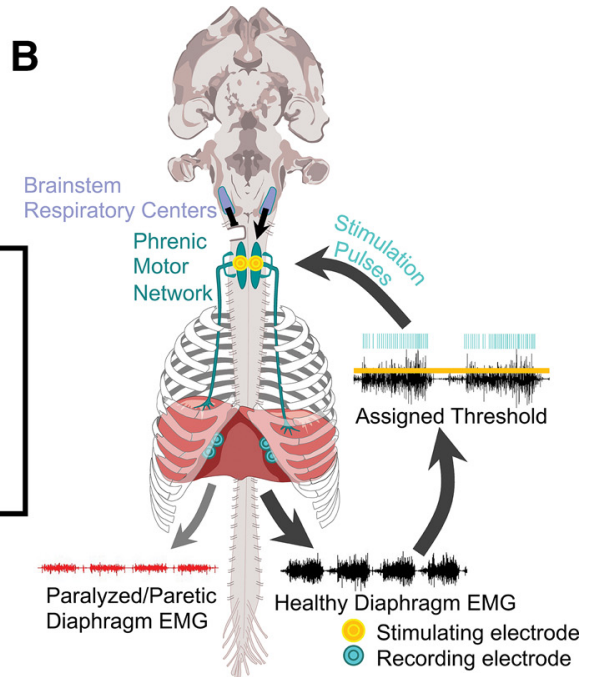

Figure 1. Experimental timeline and diagram of injury and implanted electrodes. $\boldsymbol{A}$, Rat shown with headcap and attached cable, which connects to recording and stimulation equipment. The headcap holds leads that are routed to implanted diaphragm recording and spinal epidural stimulating electrodes. On the surgery day, all rats are implanted with electrodes, and rats in appropriate groups receive a C2HS. On days $0,1,2$, and 3, sMEP and EIS are measured. Between each day's measurement, stimulated rats receive 12-20 h of CLES. B, A C2HS disrupts ipsilesional descending bulbospinal inputs from brainstem respiratory centers (purple) to the phrenic motor pool (green) resulting in paralysis/paresis of the ipsilesional hemidiaphragm while the contralesional diaphragm remains intact. Implanted diaphragm EMG electrodes (cyan) record impaired (red) and intact (black) diaphragm activity. Intact diaphragm activity exceeding a threshold triggers epidural stimulation to the phrenic motor pool delivered via implanted electrodes (yellow).

C2HS + CLES $(n=8) ;(2)$ rats with a C2HS SCl that did not receive therapy, $\mathrm{C} 2 \mathrm{HS}(n=6) ;(3)$ rats with no SCl that received CLES therapy, intact + CLES $(n=6)$; and (4) rats with no $\mathrm{SCl}$ that did not receive therapy, intact $(n=6)$. Rats received a C2HS (or sham surgery) and were instrumented with indwelling bilateral diaphragm EMG recording electrodes and bilateral cervical epidural stimulating electrodes at the C4 spinal level. After 1 to $2 \mathrm{~d}$ of postsurgical recovery, sMEP and electrochemical impedance spectroscopy (EIS) were recorded as each animal's baseline, denoted DO (Fig. 1A). In rats that received stimulation, CLES was then administered 12-20 h/d for three consecutive days, and SMEP and EIS were recorded after the stimulation period on each day (D1-D3). CLES, sMEP, and EIS methods are explained in more detail below. For analysis of SMEPs, mixed effect models were fit to peakto-peak data. This model was chosen because it is particularly well suited for hierarchically structured data. A variable indicating the comparison of interest (i.e., injury and/ or CLES therapy), the log transformation of stimulation amplitude, and the interaction term between these two variables were included in the model. The random effect was defined as the log transformation of stimulation amplitude for each rat. Values of $p<0.05$ were considered statistically significant. Additional analyses of sMEPs included motor threshold, peak time, and peak-to-peak amplitude across time bins. Motor threshold is defined as the minimum current sufficient to elicit a discernible sMEP for a given animal on a given day. Differences in motor threshold were determined by Welch's $t$ test. Peak sMEP time is defined as the time (ms) between the stimulus that evokes the SMEP and the peak of the SMEP signal.
Differences in peak time were determined via two-way ANOVA with Tukey's HSD post hoc test. Time bins were measured in $\mathrm{ms}$ from the onset of the stimulus that evokes the SMEP. Differences in time bins were determined via a mixed effects model. The log transformation of stimulus amplitude, the day of measurement, the time bin, and the interaction term between these variables were included in the model. The random effect was defined as the log transformation of stimulation amplitude for each rat. The $R$ package, report, was used to generate reports for ANOVA, Tukey's HSD, and Welch's $t$ tests (Makowski et al., 2020). To test for changes in impedance magnitude from day 0 to day 3 within each animal group, impedance magnitude at 1,10 , and $100 \mathrm{kHz}$ was extracted from the spectra. A two-way, repeated measures ANOVA was applied for each of the three magnitudes to determine whether the interaction between day and group was significant on the $1 \mathrm{~Hz}, 10 \mathrm{kHz}$, and $100 \mathrm{kHz}$ impedances. The complex impedance data were also visualized using Nyquist plots to further characterize changes in impedance from day 0 to day 3 for each group. All statistical testing was performed in RStudio 1.4.1103 software.

\section{Electrode fabrication}

Epidural stimulating electrodes were made with $10-\mathrm{cm}$ lengths of 40 AWG FEP-insulated stranded stainless-steel wires (Cooner Wire) soldered to stainless-steel pins ( $P 1$ Technologies) and set into a 6-pin Delrin electrode pedestal (P1 Technologies) secured with 2 Ton Epoxy (Devcon). The complete stimulating unit consisted of two stimulating wires for epidural implantation and one ground wire. 
Two stimulating wires had a 2-mm length of insulation shaved off $1 \mathrm{~mm}$ from the end and the exposed cut ends were capped with adhesive silicone (MED-1137, NuSil Technology). The ground wire had a 1-cm-long de-insulated end. Diaphragm EMG recording electrodes were made with $20-\mathrm{cm}$ lengths of 36 AWG PFA-insulated sevenstranded stainless-steel wires (AM Systems) soldered to stainless-steel pins and set into a six-pin electrode pedestal as described above. The complete recording unit consisted of four recording wires (two per hemidiaphragm) and one ground wire, which was fabricated as described above.

\section{Surgery, $\mathrm{SCl}$, and electrode implantation}

Rats were anesthetized with $2 \%$ isoflurane and given $2 \mathrm{mg} / \mathrm{kg}$ of Meloxicam (Patterson Veterinary) and $0.05 \mathrm{mg} /$ $\mathrm{kg}$ of buprenorphine (CIII, Patterson Veterinary) preoperatively. Rats were maintained via nose cone and a precision gas vaporizer (1-2\% isoflurane). Throughout all surgical procedures, body temperature was maintained at $37-38^{\circ} \mathrm{C}$ and level of anesthesia was periodically assessed with toe pinch and the palpebral reflex. Rats were given 4-ml subcutaneous injections of lactated ringer's solution at the start, midpoint, and completion of surgery. After laparotomy, four EMG electrodes were surgically implanted bilaterally (two leads per side) on the diaphragm muscle. A 27 -gauge needle bent at a $90^{\circ}$ angle was inserted into the superficial layer of diaphragm muscle and recording electrode wires were threaded into the needle and the needle was then withdrawn. A small 3- to 5-mm portion of the wire was de-insulated perioperatively and knots of 6-0 suture were then attached to the wire to secure it in place. After closing, rats were then placed prone, and a laminectomy was performed at C2 and C4. Epidural stimulating wires were threaded under the $\mathrm{C} 5$ lamina and sutured to the dura over $\mathrm{C} 4$ with $9-0$ suture, then at $\mathrm{C} 2$ a small incision was made in the dura followed by a $\mathrm{C} 2 \mathrm{HS}$ of the left side of the spinal cord (Fig. 1B). This injury led to immediate paralysis/paresis of the ipsilesional hemidiaphragm while leaving the contralesional diaphragm functional. $\mathrm{C} 2 \mathrm{HS}$ is an established model of upper $\mathrm{CSCl}$ and its effects are well characterized (Goshgarian et al., 1986; Fuller et al., 2006, 2008; Vinit et al., 2006; Doperalski et al., 2008; Lane et al., 2009; Sandhu et al., 2009; Lee et al., 2013; Gill et al., 2014). Musculature and skin were closed in layers with 4-0 suture. Wires from epidural stimulating and EMG recording electrodes were threaded subcutaneously to the skull, and both 6-pin electrode pedestals were affixed with stainless steel skull screws and dental acrylic. Drops of lidocaine 2\%/epinephrine 1:100,000 were locally administered to prevent excessive bleeding. Rats were housed in incubators for $24-48 \mathrm{~h}$ postoperatively at $80^{\circ} \mathrm{F}$ and $55 \%$ humidity, and buprenorphine $(0.05 \mathrm{mg} / \mathrm{kg}$; q 8-12 h) and meloxicam (5.0 mg/kg; q 24 h) were administered for $3-5 \mathrm{~d}$.

\section{Chronic CLES and diaphragm EMG recording}

Implanted epidural stimulating electrodes, diaphragm recording electrodes, and a subcutaneous reference electrode were connected to the Neurochip3 brain-computer interface (Jackson et al., 2006b; Zanos et al., 2011; Shupe et al., 2021) via a six-channel cable (P1 Technologies) plugged into the implanted headstage and electrode assembly. The Neurochip3 is a battery-powered, integrated recording, computing, and stimulating system. It was used in this experiment to record diaphragm EMG, digitize the EMG signal, and deliver CLES based on user-defined events within the EMG signal (Fig. 1B). Setting relevant recording, event, and stimulation parameters was accomplished through a MATLAB R2020a (The MathWorks) graphical user interface. Diaphragm EMG was recorded at $10 \mathrm{kHz}$ and bandpass filtered $(10 \mathrm{~Hz}$ to $1 \mathrm{kHz}$ ). Stimulation was triggered when the contralesional EMG signal exceeded roughly $80 \%$ of its maximum amplitude. When this threshold was crossed, a single pulse (biphasic, symmetric, charge-balanced, cathode leading, $0.2 \mathrm{~ms}$ per phase, square wave) was delivered differentially to the epidural stimulating electrodes. This thresholding condition resulted in stimulation being delivered in-phase with diaphragm contraction with trains at a rate of $\sim 40-100$ pulses per second. The amplitude of stimulation was determined uniquely for each rat on each day because of differing sensitivity (i.e., amplitude was kept well below that which could cause pain or discomfort). The use of unique stimulation amplitude that may vary between individuals and across time is a wellknown phenomenon in the epidural stimulation field (Atkinson et al., 2011; Angeli et al., 2018; Calvert et al., 2019; Chandrasekaran et al., 2020). Stimulation amplitudes were below motor threshold (defined as the minimum current sufficient to elicit a discernible SMEP and checked each day) for each rat and were typically between 169 and $195 \mu \mathrm{A}$ (range = $[60,260] \mu \mathrm{A} ;$ mean $=176 \mu \mathrm{A} ;$ mode $=195 \mu \mathrm{A} ; 25$ th percentile $=$ $169 \mu \mathrm{A}$; 50th percentile $=188 \mu \mathrm{A} ; 75$ th percentile $=195 \mu \mathrm{A}$ ). This stimulation was typically applied for $12-22 \mathrm{~h}$ a day for each day of the experiment (range $=[1.5,28] \mathrm{h}$; mean $=16 \mathrm{~h}$; mode $=12 \mathrm{~h}$; 25 th percentile $=12 \mathrm{~h}$; 50 th percentile $=12 \mathrm{~h}$; 75 th percentile $=22 \mathrm{~h}$ ). Stimulation duration was intended to be delivered for as long as possible but varied for several reasons including experiment/facility/personnel time constraints, batteries losing charge, and animal electrode headcaps becoming unplugged. However, this variance was recorded and accounted for. The Collapsed variables section below details how the impact of these variables on the peak-topeak amplitude outcome was tested. These variables were ultimately collapsed, and the data pooled because they did not have a significant impact on peak-to-peak amplitude. For the sake of naming convention in intact rats which would not have ipsilesional or contralesional hemidiaphragm EMG recordings, "ipsilesional" refers to the left hemidiaphragm, while "contralesional" refers to the right hemidiaphragm.

\section{sMEPs}

The sMEP serves as a useful marker of spinal excitability and is used widely in clinical and experimental settings. Here, this was used to quantify change in the excitability of the phrenic motor system (Bestmann and Krakauer, 2015). sMEPs were measured daily via diaphragm recording electrodes after the day's CLES period concluded. Diaphragm EMG signals were amplified (Model 1700 Differential AC Amplifier, AM Systems) with a gain of 
$1000 \times$ and bandpass filtered $(10 \mathrm{~Hz}$ to $5 \mathrm{kHz})$, then digitized and recorded by the data acquisition device (Power1401-3A, Cambridge Electronic Design Limited). Contralesional EMG signal was processed as a movingaverage (MA-821, CWE; time constant $50 \mathrm{~ms}$ ) before being sent to the data acquisition device. Data were recorded using Spike2 v10 software (Cambridge Electronic Design Limited). Contralesional EMG signals were used to trigger stimulus pulses on inspiration since this is the most effective at eliciting evoked potentials from the diaphragm (Sunshine et al., 2018). When this signal reached $80 \%$ of maximum inspiratory amplitude, a single pulse (biphasic, symmetric, charge-balanced, cathode leading, $0.2 \mathrm{~ms}$ per phase, square wave) was delivered differentially to the epidural stimulating electrodes at $\mathrm{C} 4$ with an interpulse interval of at least $1.5 \mathrm{~s}$ to avoid temporal summation. The stimulus intensity was increased stepwise from 100 to $600 \mu \mathrm{A}$ in 10 - or $100-\mu \mathrm{A}$ increments with 10 20 stimulus pulses at each intensity. The resulting diaphragm EMG activity evoked from each group of the stimuli were averaged to produce stimulus-triggered averages within Spike2 software. Spike2 was then used to extract peak-to-peak amplitude of the stimulus-triggered average, which was measured across 1 - to 21-ms windows after the stimulus pulse. Peak-to-peak amplitude was plotted for each rat, day, and stimulus amplitude to generate stimulus-response curves. Stimulus-response curves were generated to assess neural efficacy.

\section{EIS}

Electrochemical characterization of all electrodes was performed via EIS using an Autolab potentiostat/galvanostat (PGSTST128N, Metrohm). Before implantation, each electrode was tested in a two-electrode configuration to mimic in vivo conditions and verify that each electrode was functioning as expected. The stimulation electrode served as the working electrode, the large surface area tissue ground wire as the reference and counter electrodes, and phosphate buffered saline as the electrolyte. After implantation, EIS measurements were made using the same two-electrode set-up, with the stimulation electrode serving as the working electrode, and a large surface area stainless-steel electrode as the reference/ counter-electrode implanted subcutaneously. EIS measurements were taken by applying a small $20-\mathrm{mV}$ peak-topeak sinusoidal perturbation to the working electrode. The frequency was swept logarithmically over 20 points from $100 \mathrm{kHz}$ to $10 \mathrm{~Hz}$. The potential difference between the working electrode and the reference electrode was recorded, and the impedance was determined by performing a numerical Fourier analysis. EIS measurements were recorded daily throughout the study to monitor electrode functionality and to test for differences between groups and ipsilesional and contralesional electrodes.

\section{Software}

Software used to complete this study includes Spike2 v10, MATLAB R2020a, Python 3.8.8, and RStudio 1.4.1103. Spike2 was used to interface with the stimulation and recording hardware during SMEP sessions and to deliver stimulus pulses and record EMG. Spike2 was also used to extract relevant sMEP data (e.g., peak-to-peak amplitude) from the EMG recordings. A graphical user interface within MATLAB enabled configuration of the Neurochip3 hardware that controlled CLES. Python was used to aggregate, explore, and clean data. All statistical analysis and plotting were done within RStudio. For more details on statistical analysis, see above, Experimental design and statistical analysis.

\section{Collapsed variables}

Several variables in this study were not strictly controlled because of variability inherent in a study on freely behaving animals. These variables included the duration of CLES, time of day of SMEP measurement, and time between the end of CLES and beginning of SMEP measurement on a given day. These variables were analyzed to determine whether they affected the SMEP peak-to-peak amplitude outcome measure. They had very low correlations with peak-to-peak amplitude and had nonsignificant $p$ values and small coefficients in a multiple linear regression with peak-to-peak amplitude as the dependent variable. Thus, these variables were collapsed, and the data pooled.

\section{Results}

\section{Impact of chronic, closed-loop, cervical epidural stimulation on SMEP peak-to-peak amplitude}

Representative traces (Fig. 2A) and measurements (Fig. $2 B$ ) of peak-to-peak amplitude of stimulus-triggered averages for single rats show that peak-to-peak amplitude increases with stimulus amplitude, but robust facilitation over the course of the study only occurs for the C2HS + CLES rats. Note that the peak-to- peak amplitude increases over time (e.g., from day 0 to day 3 ) given the same stimulus amplitude, especially with increasing current. Group data (Fig. 3) show that SMEP peak-to-peak amplitude was facilitated in $\mathrm{C} 2 \mathrm{HS}+\mathrm{CLES}$ rats indicated by increased stimulus-response slopes (SRSs) for days 1-3 compared with day 0 , which was not present in other animal groups.

\section{Stimulus-response curves: C2HS + CLES versus C2HS alone}

To assess the effect of CLES, we tested the hypothesis that CLES elicits facilitation after C2HS in SMEP peak-topeak amplitude (vs C2HS alone), linear mixed effects models were fit to each day's stimulus-response data for each side, ipsilesional and contralesional, to obtain a measure of the difference between SRS of each group, $\mathrm{C} 2 \mathrm{HS}+\mathrm{CLES}$ and C2HS, for a given day and side (Fig. 4). Of the two groups that received a C2HS, those that also received CLES showed a facilitation in SMEP peakto-peak amplitude compared with those that did not receive CLES. Furthermore, it is important to note that there was no difference in ipsilesional SRSs between the two groups on day 0 , but the ipsilesional SRS was larger in $\mathrm{C} 2 \mathrm{HS}+\mathrm{CLES}$ rats than in C2HS rats on day 1 (difference estimate $\left.=169.8 \mu \mathrm{V} \cdot \log (\mu \mathrm{A})^{-1}, \mathrm{Cl}[7.1,332.5], p=0.041\right)$, day $2\left(\right.$ difference estimate $=975.8 \mu \mathrm{V} \cdot \log (\mu \mathrm{A})^{-1}, \mathrm{Cl}[287.9$, 
A

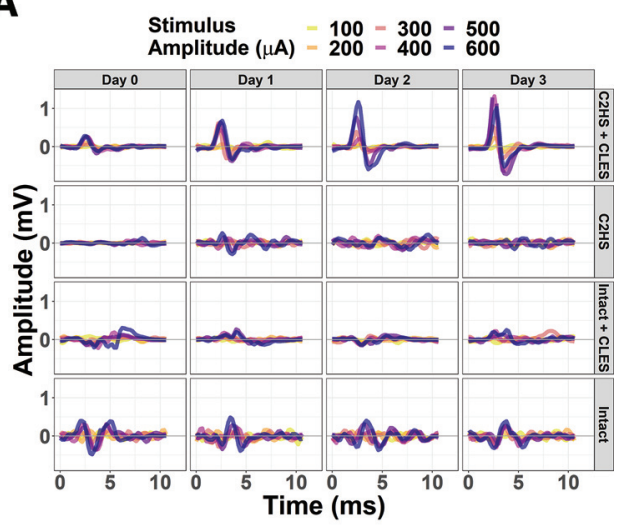

B

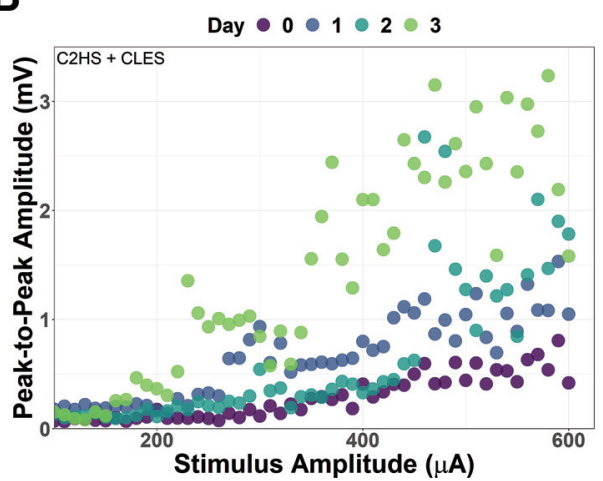

Figure 2. Representative SMEP over the course of $3 \mathrm{~d}$ of CLES. $\boldsymbol{A}$, Representative ipsilesional SMEP from a single rat in each group show that, as expected, larger stimulus amplitudes elicited larger sMEP within a given day. However, sMEP amplitude also notably increased across days for a given amplitude within the C2HS + CLES group, which we interpret as evidence of respiratory neuroplasticity. $\boldsymbol{B}$, Ipsilesional peak-to-peak amplitudes plotted from the C2HS + CLES group in $\boldsymbol{A}$ show sMEP peak-to-peak amplitude increases over time.

1663.8], $p=0.005$ ), and day 3 (difference estimate $=$ $\left.981 \mu \mathrm{V} \cdot \log (\mu \mathrm{A})^{-1}, \mathrm{Cl}[299.4,1662.6], p=0.005\right)$. The contralesional SRS was larger in C2HS + CLES rats than in C2HS rats on day 0 (difference estimate $=138.4 \mu \mathrm{V} \cdot \log (\mu \mathrm{A})^{-1}$, $\mathrm{Cl}[32.7,244.2], p=0.01$ ), day 1 (difference estimate $=$ $\left.128.1 \mu \mathrm{V} \cdot \log (\mu \mathrm{A})^{-1}, \mathrm{Cl}[16.4,239.8], p=0.025\right)$, day 2 (difference estimate $=200.2 \mu \mathrm{V} \cdot \log (\mu \mathrm{A})^{-1}, \mathrm{Cl}[69.9,330.6]$, $p=0.003$ ), and day 3 (difference estimate $=174.2 \mu \mathrm{V} \cdot \log$ $\left.(\mu \mathrm{A})^{-1}, \mathrm{Cl}[35.6,312.8], p=0.014\right)$. It is noteworthy that the difference estimates for the contralesional, intact side were smaller than the ipsilesional difference estimates and did not show an increase over time like that seen on the ipsilesional side. Because sMEPs were measured following the conclusion of CLES each day, ipsilesional data suggest that CLES after $\mathrm{C} 2 \mathrm{HS}$ elicits respiratory neuroplasticity, and when contralesional data are considered, we see that an injury may be necessary to enable CLES-induced facilitation in SRS over time.

\section{Stimulus-response curves: C2HS + CLES versus intact + CLES}

To assess the effect of the hemisection injury, we tested the hypothesis that CLES elicits a more robust facilitation of SMEP peak-to-peak amplitude in C2HS versus intact rats. Linear mixed effects models were fit to each day's stimulus-response data for each side, ipsilesional and contralesional, to obtain a measure of the difference between the SRS of each group, C2HS + CLES and intact + CLES, for a given day and side (Fig. 5). Of the two groups that received CLES, those that also had a C2HS injury showed a facilitation in SMEP compared with those that did not have a C2HS injury (intact). Ipsilesional and contralesional SRSs were larger every day in C2HS + CLES rats versus in intact + CLES rats. However, the ipsilesional side showed larger difference estimates that also increased over time. Specifically, the ipsilesional SRS was larger in C2HS + CLES rats than in intact + CLES rats on day 0 (difference estimate $\left.=334.2 \mu \mathrm{V} \cdot \log (\mu \mathrm{A})^{-1}, \mathrm{Cl}[196.6,471.8], p<0.001\right)$, day 1 (difference estimate $=227.7 \mu \mathrm{V} \cdot \log (\mu \mathrm{A})^{-1}, \mathrm{Cl}[155.3$, 300.2], $p<0.001$ ), day 2 (difference estimate $=993.4 \mu \mathrm{V} \cdot \log$ $(\mu \mathrm{A})^{-1}, \mathrm{Cl}[639.8,1346.9], p<0.001$ ), and day 3 (difference estimate $\left.=1000.1 \mu \mathrm{V} \cdot \log (\mu \mathrm{A})^{-1}, \mathrm{Cl}[773,1227.3], p<0.001\right)$. The contralesional SRS was larger in C2HS + CLES rats than in intact + CLES rats on day 0 (difference estimate $=$ $\left.135 \mu \mathrm{V} \cdot \log (\mu \mathrm{A})^{-1}, \mathrm{Cl}[84.4,185.7], p<0.001\right)$, day 1 (difference estimate $=117.7 \mu \mathrm{V} \cdot \log (\mu \mathrm{A})^{-1}, \mathrm{Cl}[65.1,170.4], p<$ 0.001 ), day 2 (difference estimate $=141.5 \mu \mathrm{V} \cdot \log (\mu \mathrm{A})^{-1}, \mathrm{Cl}$ $[56.3,226.7], p=0.013$ ), and day 3 (difference estimate $=$ $\left.142.6 \mu \mathrm{V} \cdot \log (\mu \mathrm{A})^{-1}, \mathrm{Cl}[80.2,205], p<0.001\right)$. In summary, the ipsilesional SRS was always significantly larger in C2HS + CLES animals than in intact + CLES animals, and the difference estimates increased over time. The contralesional SRS was also always larger in $\mathrm{C} 2 \mathrm{HS}+$ CLES animals than in intact + CLES animals, but the difference estimates did not show the same marked increase over time. Together, these results suggest that CLES does not cause the same degree of SMEP facilitation in intact rats as it does in rats with a C2HS. Thus, $\mathrm{C} 2 \mathrm{HS}$ may allow for apparent marked facilitation.

\section{Stimulus-response curves: ipsilesional versus contralesional}

To assess the unilaterality of the effect of CLES, we tested the hypothesis that ipsilesional sMEPs show greater facilitation compared with contralesional SMEPs within C2HS + CLES rats. Linear mixed effects models were fit to each day's stimulus- response data for each rat group to obtain a measure of the differences between the SRS of each side, ipsilesional and contralesional, for a given day and group (Fig. 6). Ipsilesional SRS was larger every day in C2HS + CLES and this result was absent in other rat groups: C2HS, intact + CLES, intact. Specifically, the SRS for C2HS + CLES rats was larger on the ipsilesional side than on the contralesional side on day 0 (difference estimate $\left.=365.1 \mu \mathrm{V} \cdot \log (\mu \mathrm{A})^{-1}, \mathrm{Cl}[275.2,454.9], p<0.001\right)$, day 1 (difference estimate $=160.4 \mu \mathrm{V} \cdot \log (\mu \mathrm{A})^{-1}, \mathrm{Cl}[115$, 205.7], $p<0.001$ ), day 2 (difference estimate $=745.6 \mu \mathrm{V} \cdot \log$ $\left.(\mu \mathrm{A})^{-1}, \mathrm{Cl}[578.9,912.4], p<0.001\right)$, and day 3 (difference estimate $\left.=750 \mu \mathrm{V} \cdot \log (\mu \mathrm{A})^{-1}, \mathrm{Cl}[580.3,919.6], p<0.001\right)$. However, C2HS alone does not facilitate SRSs over $3 \mathrm{~d}$. Specifically, the SRS for C2HS rats was larger on the ipsilesional side than on the contralesional side on day 0 (difference estimate $=134.5 \mu \mathrm{V} \cdot \log (\mu \mathrm{A})^{-1}, \mathrm{Cl}[40.4,228.7]$, 


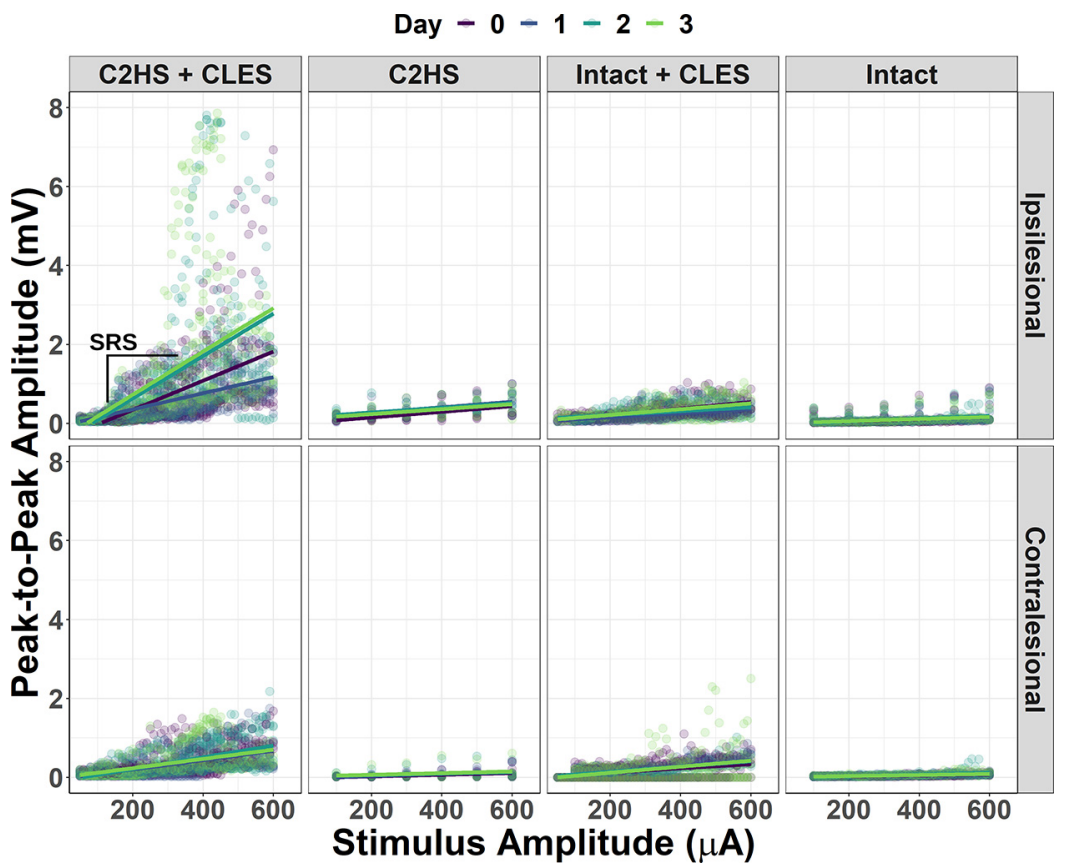

Figure 3. sMEPs, group data. All data points for all animals are plotted along with lines (stimulus-response curves) fit with simple linear regression using ordinary least squares for each group, side, and day. One stimulus-response curve has been annotated to illustrate its stimulus response slope (SRS). Ipsilesional data show an increase in the SRS across days that is most pronounced in $\mathrm{C} 2 \mathrm{HS}+\mathrm{CLES}$ rats. Contralesional data show smaller increases in the slope of fit stimulus-response curves across days compared with that seen in ipsilesional C2HS + CLES animals. This plot serves to illustrate trends seen in the aggregate data and motivate further statistical analysis. It does not communicate any statistical comparisons.

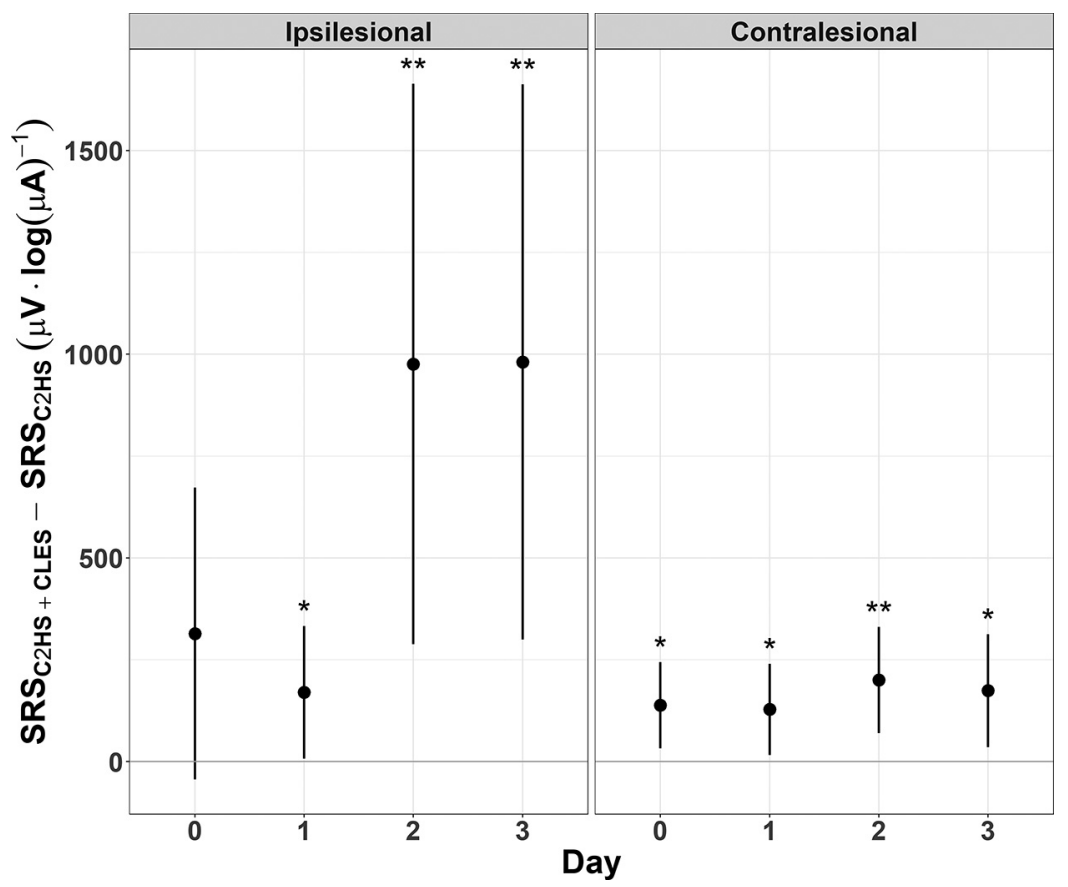

Figure 4. Differences between the SRS of C2HS + CLES rats and C2HS rats. Comparing the difference in ipsilesional SRS shows no difference between C2HS + CLES rats and C2HS rats at day 0 . However, each day thereafter, the slope for C2HS + CLES rats is significantly larger. The largest estimates of this difference are on days 2 and 3 . Contralesional data show that C2HS + CLES rats have a larger SRS than $\mathrm{C} 2 \mathrm{HS}$ rats each day, albeit with smaller difference estimates. The only comparisons tested here are between $\mathrm{C} 2 \mathrm{HS}+\mathrm{CLES}$ and C2HS rats for a given day and side (linear mixed effects model, ${ }^{*} p \leq 0.05,{ }^{* *} p \leq 0.01$; dots indicate the model's estimate; lines indicate the $95 \%$ confidence interval). Positive values here indicate that the C2HS + CLES group had a larger SRS than the $\mathrm{C} 2 \mathrm{HS}$ group. 


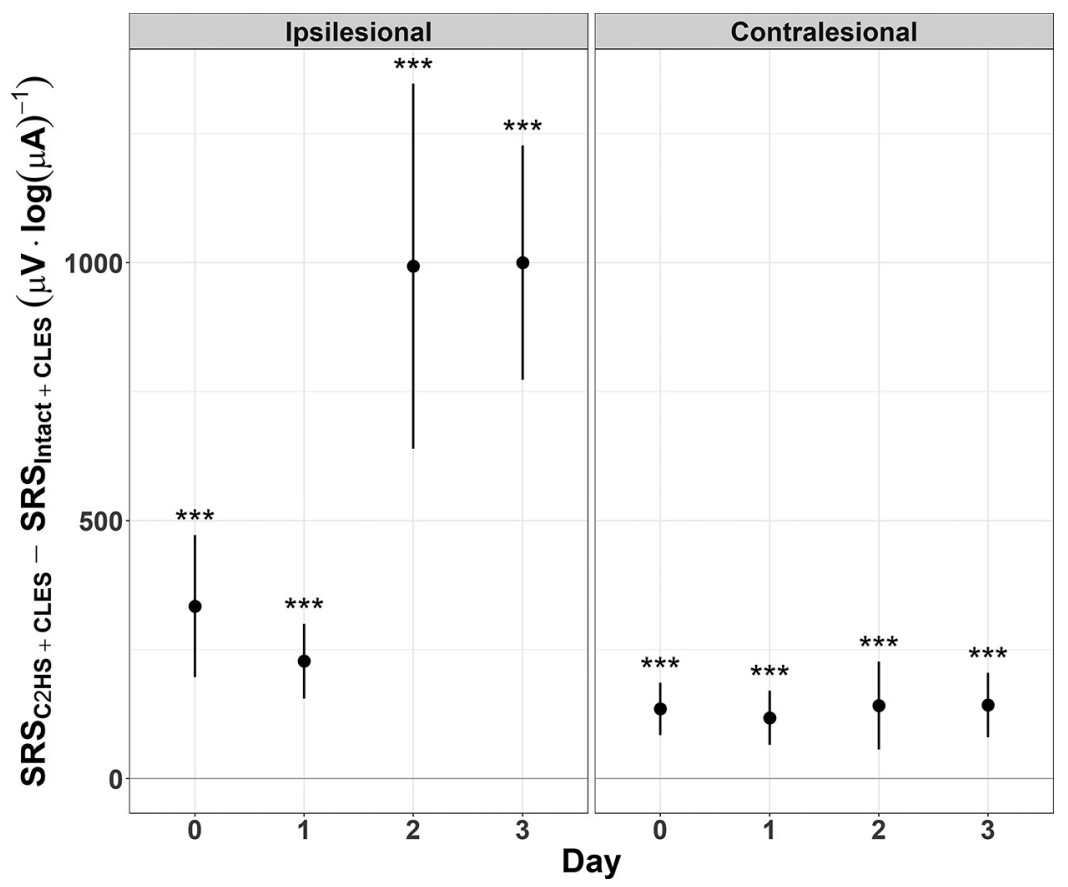

Figure 5. Differences between the SRSs of C2HS + CLES rats and intact + CLES rats. Comparing the difference in ipsilesional SRS shows that on each day, the SRS for C2HS + CLES rats is significantly larger than the SRS for intact + CLES rats, and the largest estimates occur on day 2 and day 3. Contralesional data show that C2HS + CLES rats have a larger SRS than C2HS rats each day, albeit with smaller difference estimates. The only comparisons tested here are between C2HS + CLES and intact + CLES rats for a given day and side $\left({ }^{\star \star \star} p \leq 0.001\right.$; dots indicate the model's estimate; lines indicate the $95 \%$ confidence interval). Positive values here indicate that the C2HS + CLES group had a larger SRS than the intact + CLES group.

$p=0.005)$, day 1 (difference estimate $=118 \mu \mathrm{V} \cdot \log (\mu \mathrm{A})^{-1}, \mathrm{Cl}$ $[26.4,209.6], p=0.012$ ), and day 2 (difference estimate $=$ $\left.113.9 \mu \mathrm{V} \cdot \log (\mu \mathrm{A})^{-1}, \mathrm{Cl}[23.9,203.8], p=0.013\right)$, but disappears on day 3 . This initial facilitation in ipsilesional versus contralesional sMEP stimulus-response curves for $\mathrm{C} 2 \mathrm{HS}$ rats may suggest hyperexcitability after $\mathrm{C} 2 \mathrm{HS}$. It is important to note that these SMEP SRS estimates for $\mathrm{C} 2 \mathrm{HS}$ rats are not as large as those for C2HS + CLES rats, especially on days 2 and 3. In intact + CLES rats, we see no persistent facilitation across time, and any significant difference estimates are relatively small in magnitude. Specifically, the SRS for intact + CLES rats was larger on the ipsilesional side than on the contralesional side on day 0 (difference estimate $=40.6 \mu \mathrm{V} \cdot \log$ $\left.(\mu \mathrm{A})^{-1}, \mathrm{Cl}[1.9,79.4], p=0.04\right)$; was smaller on the ipsilesional side than on the contralesional side on day 1 (difference estimate $\left.=-40.6 \mu \mathrm{V} \cdot \log (\mu \mathrm{A})^{-1}, \mathrm{Cl}[-76.1,-5], p=0.025\right)$ and was not different between the ipsilesional and contralesional side on days 2 and 3 . Lastly, intact animals showed some difference between ipsilesional and contralesional SRS, but these estimates are small in magnitude and did not increase over time. Specifically, the SRS for intact rats was larger on the ipsilesional side than on the contralesional side on day 0 (difference estimate $=37 \mu \mathrm{V} \cdot \log (\mu \mathrm{A})^{-1}, \mathrm{Cl}[5,69], p=0.023$ ) and on day 1 (difference estimate $=25.4 \mu \mathrm{V} \cdot \log (\mu \mathrm{A})^{-1}, \mathrm{Cl}[0.4$, 50.5], $p=0.047$ ); was not different between the ipsilesional and contralesional side on day 2; and was larger on the ipsilesional side than on the contralesional side on day 3 (difference estimate $\left.=29.4 \mu \mathrm{V} \cdot \log (\mu \mathrm{A})^{-1}, \mathrm{Cl}[3.2,55.6], p=0.028\right)$. In summary, these models indicate that $\mathrm{C} 2 \mathrm{HS}$ alone caused some initial facilitation, which disappeared by day 3 , and when paired with CLES, the facilitation markedly increases over time.

\section{Stimulus-response curves: difference from day 0}

To assess the temporal effect of the CLES, we tested the hypothesis that SMEP peak-to-peak amplitude facilitated in C2HS + CLES rats on days 1, 2, and 3 versus day 0 . Linear mixed effects models were fit to each side's stimulus-response data for each rat group to obtain a measure of the differences between the SRS on day 0 and each subsequent day (days 1-3), for a given side and group (Fig. 7). We found that only in the ipsilesional SRS of the C2HS + CLES group is facilitation present from day 0 to subsequent days. Specifically, the ipsilesional SRS for C2HS + CLES rats was not different from day 0 on day 1 ; was larger than day 0 on day 2 (difference estimate $=415.8 \mu \mathrm{V} \cdot \log (\mu \mathrm{A})^{-1}, \mathrm{Cl}$ $[228.8,602.9], p<0.001)$; and was larger than day 0 on day 3 (difference estimate $=419.4 \mu \mathrm{V} \cdot \log (\mu \mathrm{A})^{-1}$, Cl $[230.8$, 607.9], $p<0.001)$. The contralesional SRS for C2HS + CLES rats was not different from day 0 on day 1,2 , or 3 . For $\mathrm{C} 2 \mathrm{HS}$ rats, both the ipsilesional SRS and contralesional SRS were not different from day 0 on day 1,2 , or 3 . For intact + CLES rats, the ipsilesional SRS was not different from day 0 on day 1,2 , or 3 . The contralesional SRS for intact + CLES rats was not different from 0 on day 1 ; was not different from 0 on day 2; and was larger than 0 on day 3 (difference estimate $=37.1 \mu \mathrm{V} \cdot \log (\mu \mathrm{A})^{-1}, \mathrm{Cl}[2.9,71.3]$, $p=0.034$ ). For intact rats, the ipsilesional SRS was not different from day 0 on day 1,2 , or 3 . Interestingly, the 


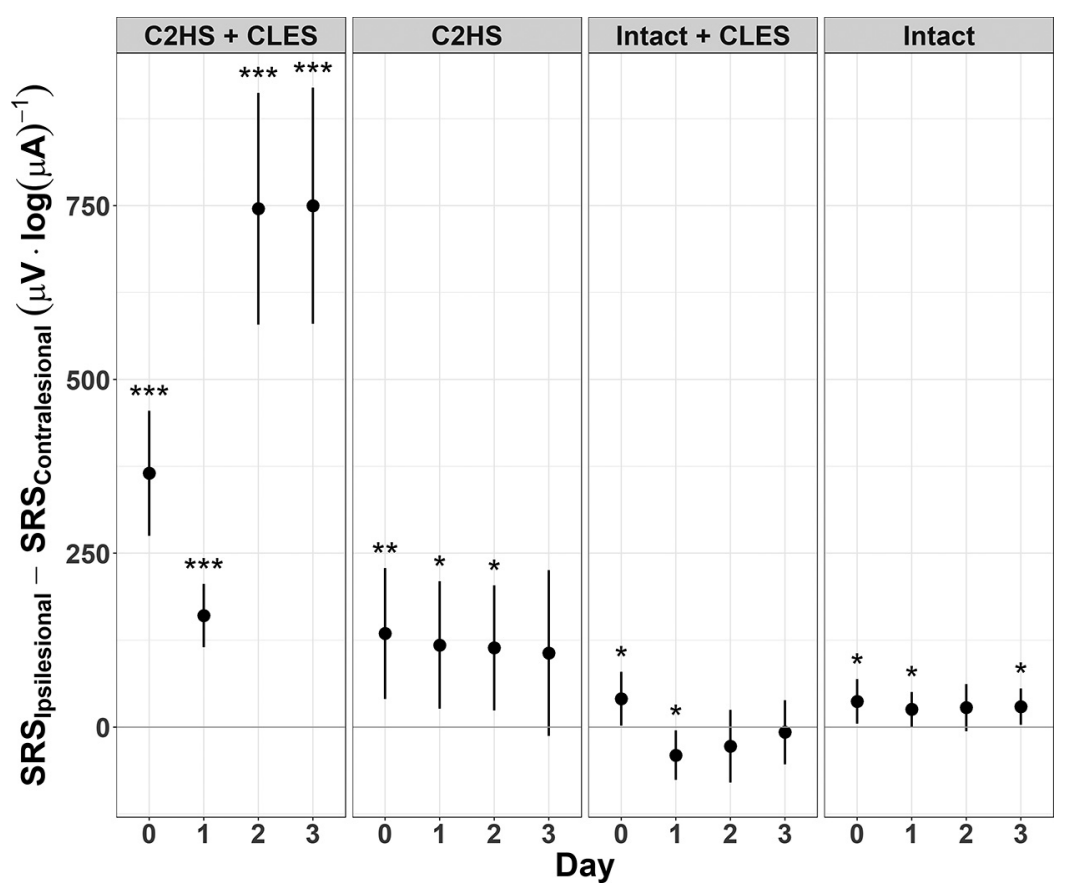

Figure 6. Differences between the ipsilesional and contralesional SRSs for each rat group. For C2HS + CLES rats, the ipsilesional SRS is larger than the contralesional SRS each day, and the largest differences occur on days 2 and 3 . For C2HS rats, ipsilesional SRS is larger than the contralesional SRS on days 0,1 , and 2. There is no difference on day 3 . For intact + CLES rats, ipsilesional SRSs are larger on day 0 and smaller on day 1 than the contralesional SRS. There is no difference on day 2 or 3 . For intact rats, the ipsilesional SRS is larger than the contralesional SRS on days 0,1 , and 3. There is no difference on day 2 . It is noteworthy that the only group that shows ipsilesional SRSs that are larger than contralesional SRSs each day is the C2HS + CLES group. The only comparisons tested here are between the ipsilesional and contralesional side for a given group on a given day $\left({ }^{*} p \leq 0.05\right.$, ${ }^{* *} p \leq 0.01$, ${ }^{\star \star \star} p \leq 0.001$; dots indicate the model's estimate; lines indicate the $95 \%$ confidence interval). Positive values here indicate that the ipsilesional side had a larger SRS than the contralesional side.

contralesional SRS for intact rats was larger than day 0 on day 2 (difference estimate $=26.9 \mu \mathrm{V} \cdot \log (\mu \mathrm{A})^{-1}, \mathrm{Cl}[11.3$, 42.4], $p=0.001$ ) although not different from 0 on day 1 on day 3. This effect, however, was small. Collectively, these data suggest that CLES elicits respiratory neuroplasticity after $\mathrm{C} 2 \mathrm{HS}$ because there is a persistent change in the SRS over time in $\mathrm{C} 2 \mathrm{HS}+\mathrm{CLES}$ rats on the ipsilesional side. No other groups show this persistent facilitation. Additionally, note that any significant difference estimates not in ipsilesional C2HS + CLES rats were of such low magnitude that they may be considered negligible.

\section{Motor threshold}

On day 3 of the experiment, the amount of current necessary to evoke an SMEP was significantly lower in rats that received CLES compared with rats that did not receive CLES (Fig. 8A). The Welch two-sample $t$ test testing the difference of motor threshold by therapy (mean in group $\mathrm{No}=317.08 \mu \mathrm{A}$, mean in group $\mathrm{Yes}=198.40 \mu \mathrm{A}$ ) suggests that the effect is negative, statistically significant, and large (difference $=-118.68 \mu \mathrm{A}, 95 \% \mathrm{Cl}[54.61$, 182.76], $t_{(33.28)}=3.77, p<0.001$; Cohen's $d=1.31,95 \%$ $\mathrm{Cl}[0.55,2.05])$. There was no difference between the ipsilesional and contralesional side. The presence or absence of $\mathrm{C} 2 \mathrm{HS}$ did not significantly affect motor threshold. These results suggest that $3 \mathrm{~d}$ of CLES to the cervical spinal cord increases the excitability of the phrenic motor network.

\section{Time-to-peak amplitude}

The sMEP peak time in the intact + CLES group was significantly higher than in the C2HS + CLES group $(2.04 \mathrm{~ms}$, $\mathrm{Cl}[1.25,2.83], p<0.001)$ and the intact group $(2.26 \mathrm{~ms}, \mathrm{Cl}$ $[1.29,3.22], p<0.001$; Fig. 8B). The two-way ANOVA suggests that: the main effect of Therapy is statistically significant $\left(F_{(1,518)}=8.85, p=0.003\right.$; Eta2 (partial) $=0.02,90 \% \mathrm{Cl}$ [3.36e-03, 0.04]); the main effect of injury is statistically significant $\left(F_{(1,518)}=32.66, p<0.001\right.$; Eta2 (partial) $=0.06,90 \%$ $\mathrm{Cl}[0.03,0.10])$; and the interaction between Therapy and injury is statistically significant $\left(F_{(1,518)}=13.85, p<0.001\right.$; Eta2 $($ partial $)=0.03,90 \% \mathrm{Cl}[8.16 \mathrm{e}-03,0.05])$. CLES may show differential effects on the injured versus intact phrenic motor system, which further supports that $\mathrm{C} 2 \mathrm{HS}$ itself may play a role in the ability to detect CLES-induced facilitation

\section{Peak-to-peak amplitude across time bins}

The SRS of the ipsilesional peak-to-peak amplitude was significantly larger on day 3 versus on day 0 in the C2HS + CLES animals in the 9- to 13-ms time bin (difference estimate $=3.06 \mu \mathrm{V} \cdot \log (\mu \mathrm{A})^{-1}, \mathrm{Cl}[1.54,4.57], p<$ 0.001 ; Fig. $8 C$ ). This difference is larger at larger stimulus amplitudes demonstrating that after C2HS and CLES, 


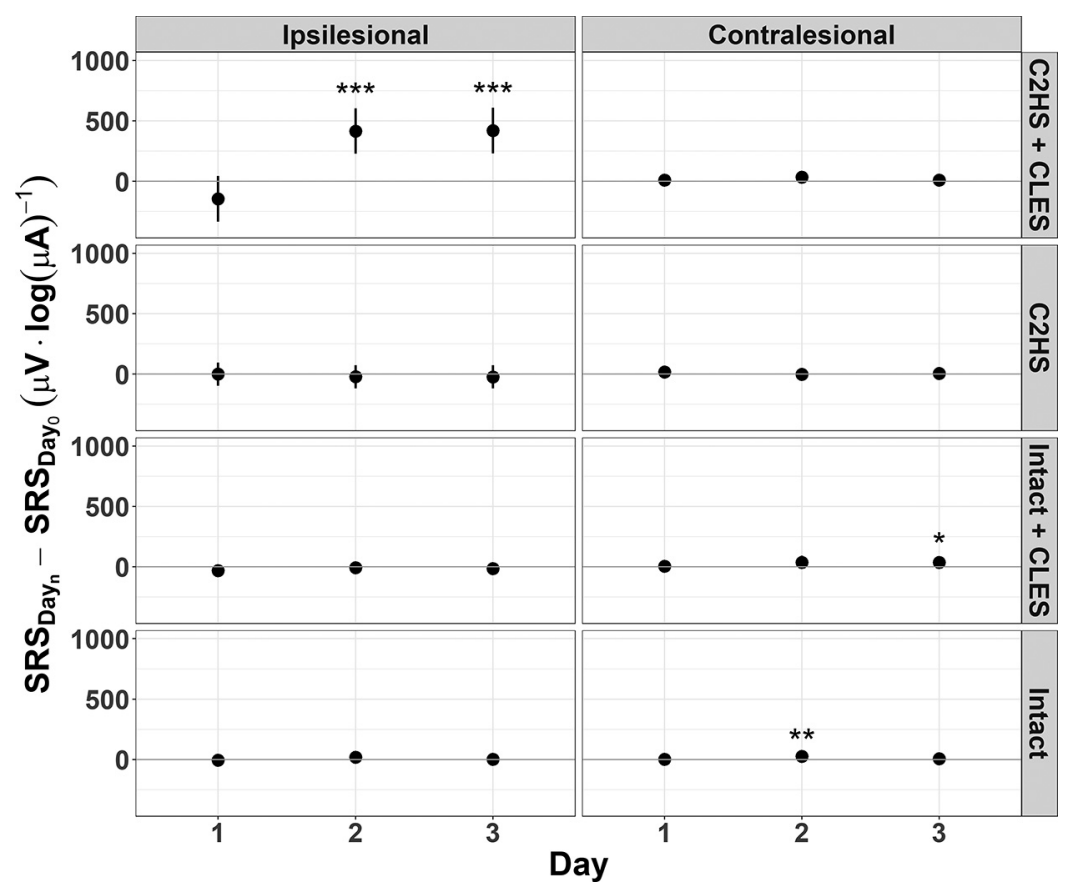

Figure 7. Differences between the SRSs for each rat group and each side. For every rat group and each side, there is never a significant difference between the day 1 SRS and the day 0 SRS. However, for the ipsilesional side of C2HS + CLES rats, the day 2 and day 3 SRSs are larger than the day 0 SRS. The only other significant differences are for contralesional side of intact + CLES rats on day 3 and the contralesional side of intact rats on day 2. However, these differences are noticeably smaller than the differences seen for ipsilesional C2HS + CLES SRSs. The only comparisons tested here are between a given day and day 0 for a given side and rat group $\left({ }^{\star} p \leq 0.05,{ }^{* *} p \leq 0.01,{ }^{* *} p \leq 0.001\right.$; dots indicate the model's estimate; lines indicate the $95 \%$ confidence interval). Positive values here indicate that the given day had a larger SRS than day 0.

peak-to-peak amplitude is increased in longer latency time domains. These results suggest that CLES may enable the recruitment of polysynaptic pathways on day 3 and further investigation is warranted. In addition, the effect was much more pronounced on the ipsilesional side suggesting that $\mathrm{C} 2 \mathrm{HS}$ may be necessary for CLES to elicit these effects.

\section{EIS}

No significant differences in impedance magnitude were found between groups or days (Fig. 9). The main effects of day $\left(F_{(1,30)}=0.45, p=0.506\right.$; Eta2 $($ partial $)=0.01,90 \% \mathrm{Cl}$ $[0.00,0.15])$ and group $\left(F_{(3,30)}=1.07, p=0.376 ;\right.$ Eta2 (partial) $=0.10,90 \% \mathrm{Cl}[0.00,0.23])$ are not statistically significant. The interaction between day and group is not significant $\left(F_{(3,30)}=0.10, p=0.960\right.$; Eta2 $($ partial $)=9.78 \mathrm{e}-03,90 \% \mathrm{Cl}$ $[0.00,0.00])$. No differences were found at 10 nor $100 \mathrm{kHz}$ (data not shown). This validates that the facilitation observed in SMEPs is not because of changing physics of the electrode nor because of biological encapsulation. The formation of a semi-circular arc at high frequencies in the Nyquist space (Fig. 9A) is indicative of a possible foreign body response, which could be more impactful at longer timepoints (Williams et al., 2007; Wilks et al., 2012).

\section{Discussion}

To our knowledge, this is the first report that CLES elicits spinal respiratory neuroplasticity after $\mathrm{C} 2 \mathrm{HS}$ in freely behaving rats with $\mathrm{cSCl}$. Our findings demonstrate that CLES administered to the region of the phrenic motor nucleus enhances evoked diaphragm motor output and that the magnitude of this enhancement increases across multiple days of therapeutic stimulation. Interestingly, this effect was specific to the ipsilesional diaphragm in C2HSinjured rats (i.e., the effect was not as robust in the contralesional diaphragm). Furthermore, although we observed a small and variable increase in amplitudes of sMEP after CLES in intact rats, it was negligible, suggesting that the injury itself may increase chances for plasticity. In addition, CLES reduced motor thresholds and features appeared in longer-latency time domains of the sMEPS, indicating possible recruitment of synapses. Although mechanisms underlying these changes are unknown and untested, we postulate that these effects could be because of activity-dependent synaptic plasticity. These results are exciting and suggest a potential new route of exploration for use of epidural stimulation as a respiratory therapeutic after cSCl.

\section{Enabling activation of the phrenic motor network with subthreshold epidural stimulation}

Many available therapies, such as functional electrical stimulation (FES), activate respiratory muscles per se versus the neural network controlling them. Unfortunately, direct muscle stimulation produces muscle fatigue, whereas spinal stimulation can enable fatigue-resistant contractions in a more 


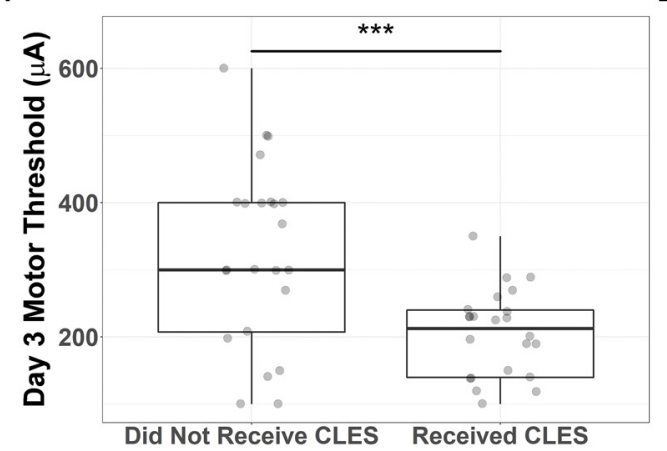

B

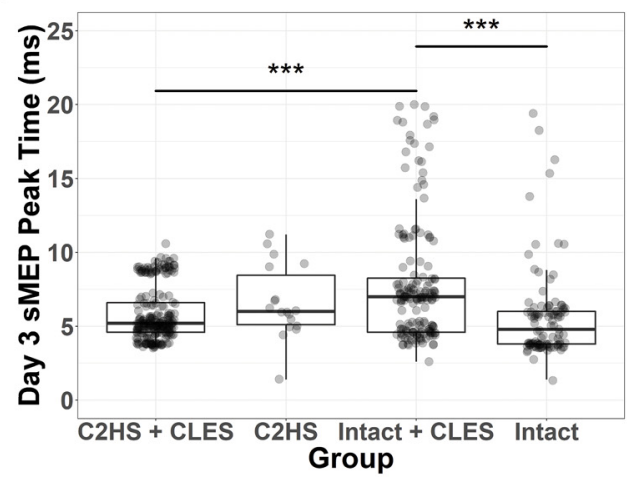

C

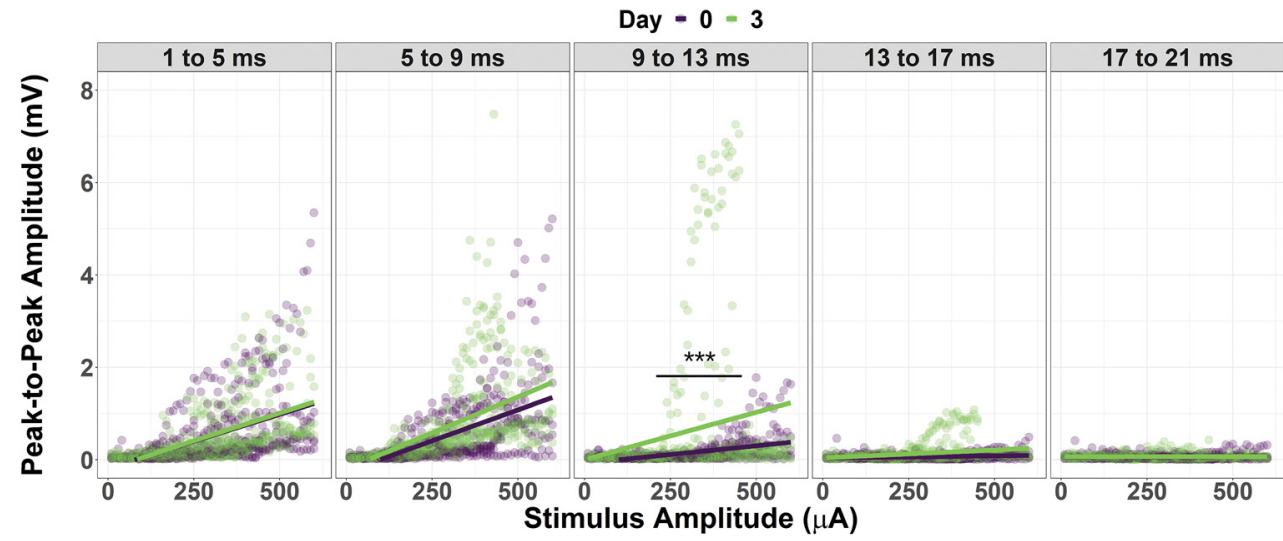

Figure 8. Additional analyses of SMEP. $\boldsymbol{A}$, Day 3 motor threshold is significantly lower in rats that received CLES than in rats that did not receive CLES $\left({ }^{\star * \star} p \leq 0.01\right)$. The presence of $\mathrm{C} 2 \mathrm{HS}$ had no effect. $\boldsymbol{B}$, The peak time of sMEP on day 3 differed significantly across groups. Intact + CLES rats had larger time-to-peak amplitude values than intact rats and $\mathrm{C} 2 \mathrm{HS}+\mathrm{CLES}$ rats $\left(^{\star \star \star} p \leq 0.001\right)$. $\boldsymbol{C}$, In C2HS + CLES rats, ipsilesional peak-to-peak amplitude was significantly larger in the 9- to 13-ms time bins on day 3 compared with day $0\left({ }^{* * *} p \leq 0.001\right)$. Data in $\boldsymbol{A}$ and $\boldsymbol{B}$ presented as box and whisker plots displaying the 25 th, 50 th, and 75 th percentile. Whiskers extend to the maximum and minimum data values that lie within 1.5 times the interquartile range from the hinges.

"natural," coordinated fashion (Moritz, 2018). Thus, many of the reported epidural stimulation paradigms are administered below motor threshold. Chronic, severe SCl greatly reduces the baseline level of spinal network activity, because of the interruption of crucial supraspinal descending inputs (Harkema et al., 2011; Angeli et al., 2014; Gerasimenko et al., 2015; Grahn et al., 2017). Subthreshold epidural stimulation has been hypothesized to greatly improve chances of sensorimotor volitional control by increasing local excitability nearer to motor threshold. Stimulation at current intensities below that which trigger motor activation interacts with ongoing network activity (Ozen et al., 2010) and likely in a way that synchronizes activity of the individual neurons comprising the circuit (Francis et al., 2003; Selverston et al., 2009). Although weak fields do not initiate action potentials (an all-or-none response), they may generate a graded modulation of neurotransmitter release (Mendelson, 1971) thereby potentially increasing resting membrane potentials. Subthreshold stimulation may act similarly on interneuronal or propriospinal networks (Radman et al., 2009). Thus, by initiating a spectrum of subthreshold depolarizations, sensory and propriospinal sources can also be integrated for the fine-tuned modulation required for breathing. Here, we show that the motor threshold for all rats treated with CLES decreased compared with those that did not receive stimulation, indicating components within the phrenic motor network had been potentially augmented from low responsive or nonresponsive to a level whereby evoked potentials could be initiated more easily. In addition, this elevated excitability appeared to enable the appearance of so-called "late responses" (Gerasimenko et al., 2006) characterized by features of the evoked response appearing in later time bins. Late responses are likely to represent polysynaptic events elicited through, in our case, phrenic-related interneuronal populations (Lane et al., 2008). Here, we found that higher amplitude peaks appeared in longerlatency time bins $(9-13 \mathrm{~ms})$ after $3 \mathrm{~d}$ of stimulation in injured rats that received CLES (although only in the ipsilesional recordings). We hypothesize that features appearing in later time bins may be evidence of this polysynaptic response (Monfils and Teskey, 2004) in respiratory motor circuits. Interneuronal (Lane et al., 2009; Sandhu et al., 2009; Lane, 2011) pathways near the phrenic motor nucleus have been suggested to play an important role in respiratory neuroplasticity after $\mathrm{SCl}$. Additionally, these interneurons may modulate the activity of respiratory motoneurons normally or during 


\section{A}

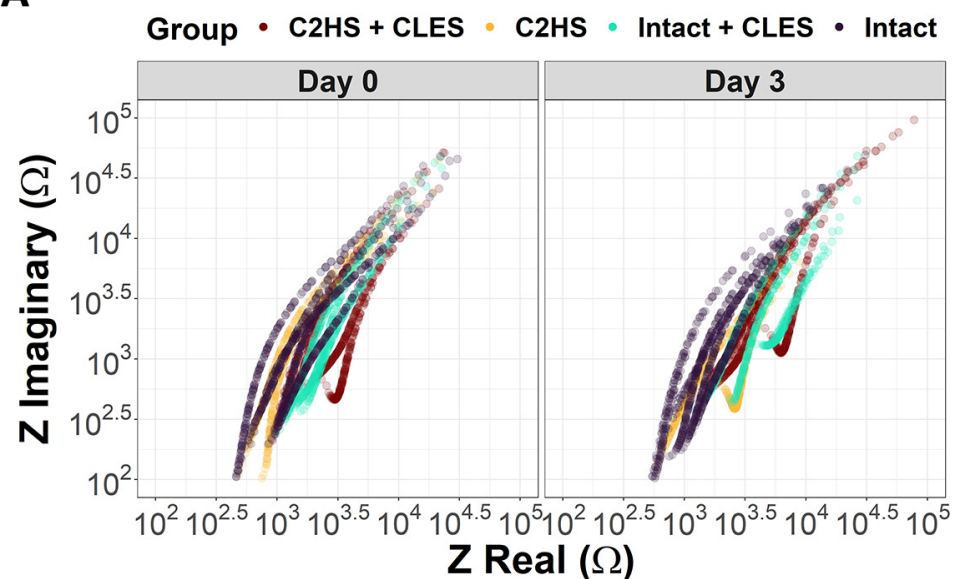

B

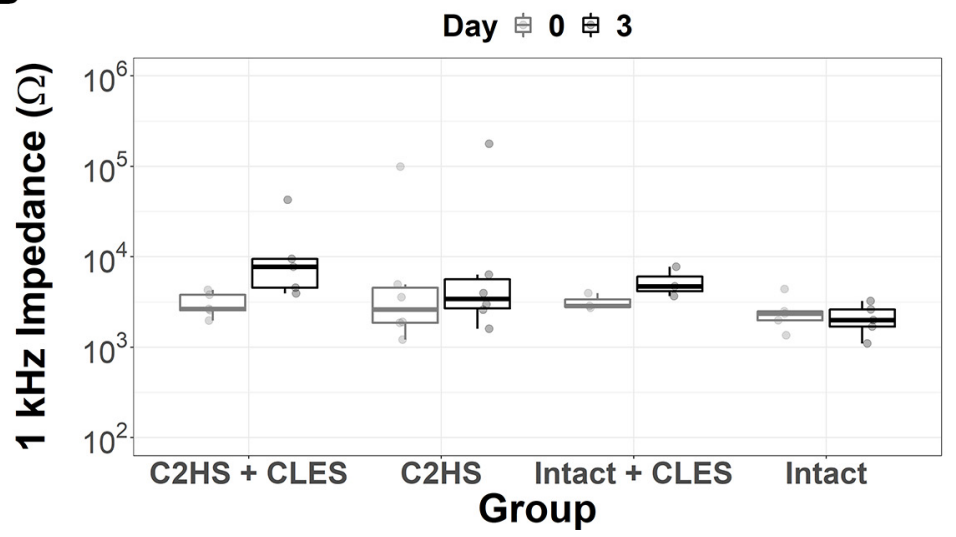

Figure 9. Day 0 and day 3 impedance data from epidural stimulating electrodes. $\boldsymbol{A}$, Nyquist plots show imaginary impedance ( $Z$ imaginary) versus real impedance ( $Z$ real). This reveals what appears to be the beginnings of a semi-circular arc at high frequencies, indicative of a possible foreign body response. $\boldsymbol{B}$, No significant differences in impedance magnitude between groups or days were found suggesting that changes in SMEP reported here are not because of changing physics of the electrode and that any potential electrode encapsulation did not affect the impedance. Data in $\boldsymbol{B}$ presented as box and whisker plots displaying the 25th, 50th, and 75th percentile. Whiskers extend to the maximum and minimum data values that lie within 1.5 times the interquartile range from the hinges.

conditions of altered respiratory drive (Kirkwood et al., 1993; Streeter et al., 2017, 2020).

\section{Potential mechanisms of CLES-induced enhancement of evoked responses}

Neuroplasticity is a fundamental property of the neural system controlling breathing (Mitchell and Johnson, 2003). We present a form of CLES-induced facilitation of evoked potential magnitude demonstrating at least shortterm plasticity since 1) SMEP were recorded after the therapeutic stimulation was turned off for $\sim 60-120 \mathrm{~min}$, and 2) SMEP magnitude progressively increased over several days in $\mathrm{C} 2 \mathrm{HS}$ rats treated with CLES. However, the mechanisms giving rise to CLES-induced enhancement of diaphragm SMEPs are unknown. We do know that the spinal cord retains its ability to learn motor behaviors after SCl via activity-dependent mechanisms (Forssberg et al., 1975; Hodgson et al., 1994; Edgerton et al., 2004; Gad et al., 2013). Restoration of motor function via epidural stimulation in individuals with $\mathrm{SCl}$ may partially rely on activity-dependent plasticity of spinal and supraspinal networks (Taccola et al., 2018). Emerging evidence suggests that long-term, closed-loop stimulation in other neural systems may enable lasting neurorehabilitation via activity-dependent processes (Jackson et al., 2006a; Jackson and Zimmermann, 2012; Nishimura et al., 2013). Mechanisms have been postulated as relying on presynaptic and postsynaptic functional changes (Bliss and Collingridge, 2013), monoaminergic modulation (Mauelshagen et al., 1998), and new synapse formation all within the neuromotor network of interest because of the activation of sensory afferents specific to the task (Lavrov et al., 2008; Rejc et al., 2015). In this case, phrenic afferents include large- diameter myelinated fibers (Groups la, lb, and II) that discharge in phase with contraction of the diaphragm (Nair et al., 2017) as well as smaller-diameter, myelinated free nerve endings (Group III) and unmyelinated C fibers (Group IV; Nair et al., 2017). Modeling studies report that epidural stimulation is most likely activating large-diameter, myelinated A-fibers which presumably increases excitability to allow the combination of afferent feedback and any residual descending input to 
facilitate diaphragm motor output (Taccola et al., 2018). Electrical stimulation of the nervous system also leads to intracellular calcium influx, thereby initiating an ERK-dependent increase in BDNF expression (Wenjin et al., 2011) in the spinal cord (Huie et al., 2012). Indeed, in paradigms of stimulation-induced spinal learning, effects were dependent on the pattern of stimulation, NMDA receptor activation, protein synthesis, and BDNF release (Baumbauer et al., 2009). Collectively, these reports suggest that patterned electrical stimulation of the cervical spinal cord could potentially drive taskspecific neuronal activity between residual bulbospinal inputs, afferent sensory inputs, phrenic interneurons and phrenic motoneurons. Thus, delivering stimulation in phase with endogenous respiration may increase the strength and number of terminals in the phrenic motor nucleus via spike-timing-dependent-like plasticity (Nishimura et al., 2013; McPherson et al., 2015; Ganzer et al., 2018). Although we have not tested these hypotheses here, we speculate that CLES-induced respiratory neuroplasticity may be induced via similar mechanisms.

\section{Epidural electrode placement}

This proof-of-principle study marks the first exploration of epidural stimulation to restore respiratory function after an upper $\mathrm{CSCl}$ in freely behaving rats. Because these were the first studies of their kind, our rationale to implant the two stimulating electrodes bilaterally over the C4 spinal segment was based largely on anatomy and published reports of phrenic motor circuitry and plasticity (for review, see Malone et al., 2021). Modeling (Struijk et al., 1993; Murg et al., 2000; Capogrosso et al., 2013; Minassian et al., 2016) and cadaver (Swiontek et al., 1976) studies suggest that current is unlikely to spread throughout many segments of the cord. Although the motor neurons within the phrenic motor nucleus typically span from spinal segments $\mathrm{C} 3$ to $\mathrm{C} 5$, the majority $(\sim 70 \%)$ lie within the C4 spinal segment (Goshgarian and Rafols, 1981; Gottschall, 1981). We postulate that CLES is not necessarily directly activating motor neurons per se (e.g., epidural stimulation is hypothesized to activate large diameter afferent fibers first); the cervical dorsal roots carrying diaphragmatic afferents insert at C3-C6 with $\sim 68 \%$ of soma lying within the region of the C4 segment. Subsequent modulation from dorsal inputs to ventral outputs would then occur where the largest proportion of this motor pool resides (C4). Another crucially important C4 neuronal population would include prephrenic interneurons (Lane et al., 2008, 2009; Lane, 2011) which, if activated, could aid in elevating network excitability and lead to respiratory motor recovery (Zholudeva et al., 2018). And finally, crossed latent pathways caudal to the $\mathrm{C} 2$ injury (i.e., the crossed phrenic pathway; Goshgarian, 2003, 2009) prompted us to consider a bilateral rather than unilateral placement since the potential for eliciting respiratory plasticity is high in this descending, decussating bulbospinal input to phrenic motor neurons. Other substrates on with CLES could act to elicit plasticity in the $\mathrm{C} 4$ region include the dorsal root ganglia (Van Buyten et al., 2015) and glia
(Tawfik et al., 2010). In addition, propriospinal neurons at C4 could also allow for recruitment of segmental circuits known to play a role in recovery of respiration after $\mathrm{SCl}$ (Jensen et al., 2019). Importantly, low-resistivity cerebrospinal fluid allows for current to flow around the spinal cord (Baumann et al., 1997), suggesting that CLES could also be directly modulating efferent outflow.

Here, we show that CLES-induced facilitation in ipsilesional SMEPs is a much more robust phenomenon than in contralesional diaphragm. While the contralesional phrenic-to-diaphragm network is functional in this model of $\mathrm{SCl}$, it is not correct to state that it is "normal." In fact, both compensatory plasticity to maintain appropriate ventilation (Lee and Hsu, 2017) as well as diminished responses (vs ipsilesional; Lee et al., 2015) to therapeutics have been reported. We also see a bilaterally attenuated motor threshold and recruitment of polysynaptic pathways ipsilesionally after CLES. Collectively, these data indicate a complex story in which the roles of spinal substrates, latent crossed pathways, as well as cellular mechanistic underpinnings of ipsilesional versus contralesional networks after injury must be investigated to truly advance to a therapeutic outcome.

\section{Limitations}

While we demonstrate that CLES can elicit SMEP plasticity after $\mathrm{C} 2 \mathrm{HS}$, more evidence is needed to assert CLES as a rehabilitative respiratory therapy. Testing the rehabilitative potential of CLES will likely require both longer timepoints postinjury and ultimately need to be repeated and validated in rats with chronic SCl. Here, we have hypothesized that it is the closed-loop nature of the paradigm itself that is beneficial in restoring respiratory function after $\mathrm{cSCl}$ for the mechanistic reasons outlined above. Many forms of activity-dependent plasticity require precise timing relationships between presynaptic and postsynaptic activation. Thus, spinal respiratory circuits may be especially responsive and amenable to this approach since pattern sensitivity is a fundamental property of spinal respiratory motor plasticity. However, we have not directly tested this hypothesis here and further work using open-loop or out-of-phase stimulation parameters is required.

Lastly, MEPs serve as a marker of spinal excitability and are used clinically to assess sensorimotor function after $\mathrm{SCl}$. Our current results show enhancement of SMEPs after CLES indicating robust respiratory neuroplasticity. However, we acknowledge that while sMEPS can give insight into the physiology of presynaptic and postsynaptic neural circuits, it is important to link the electrophysiological outcomes to behavior (e.g., breathing recovery). We postulate that an enhancement of sMEP peak to peak amplitude translates to increased synaptic strength with the potential for respiratory recovery. Indeed, enhanced evoked potential amplitude after exposure to other known respiratory neuroplasticity-inducing stimuli (e.g., intermittent hypoxia, cervical spinal A2a receptor agonism) is correlated with increased respiratory motor output (Fuller et al., 2003; Golder et al., 2008; Perim et al., 2021) and ventilation (Golder et al., 2008) in rats. Future experiments are 
required to understand how CLES affects recovery of breathing after $\mathrm{CSCl}$, but we posit that this is the first step toward developing CLES as a true rehabilitative therapy in this space.

In conclusion, here we demonstrate that CLES induces at least short-term plasticity in SMEP peak-to-peak amplitude after $\mathrm{C} 2 \mathrm{HS}$. To our knowledge, this is the first exploration of CLES-induced plasticity in the respiratory motor control system in freely behaving rats. This study establishes the potential of CLES to promote enduring functional recovery of breathing ability. Although mechanisms of this form of plasticity are unknown, CLES shows great potential as a neuromodulatory strategy to restore breathing function in individuals with severe cSCl, potentially improving the quality of life for thousands of people dependent on mechanical ventilation for survival.

\section{References}

Angeli CA, Edgerton VR, Gerasimenko YP, Harkema SJ (2014) Altering spinal cord excitability enables voluntary movements after chronic complete paralysis in humans. Brain 137:1394-1409.

Angeli CA, Boakye M, Morton RA, Vogt J, Benton K, Chen Y, Ferreira CK, Harkema SJ (2018) Recovery of over-ground walking after chronic motor complete spinal cord injury. N Engl J Med 379:1244-1250.

Ardell JL, Cardinal R, Vermeulen M, Armour JA (2009) Dorsal spinal cord stimulation obtunds the capacity of intrathoracic extracardiac neurons to transduce myocardial ischemia. Am J Physiol Regul Integr Comp Physiol 297:R470-R477.

Ardell JL, Cardinal R, Beaumont E, Vermeulen M, Smith FM, Andrew Armour J (2014) Chronic spinal cord stimulation modifies intrinsic cardiac synaptic efficacy in the suppression of atrial fibrillation. Auton Neurosci 186:38-44.

Atkinson L, Sundaraj SR, Brooker C, O'Callaghan J, Teddy P, Salmon J, Semple T, Majedi PM (2011) Recommendations for patient selection in spinal cord stimulation. J Clin Neurosci 18:12951302.

Baumann SB, Wozny DR, Kelly SK, Meno FM (1997) The electrical conductivity of human cerebrospinal fluid at body temperature. IEEE Trans Biomed Eng 44:220-223.

Baumbauer KM, Huie JR, Hughes AJ, Grau JW (2009) Timing in the absence of supraspinal input II: regularly spaced stimulation induces a lasting alteration in spinal function that depends on the NMDA receptor, BDNF release, and protein synthesis. J Neurosci 29:14383-14393.

Bestmann S, Krakauer JW (2015) The uses and interpretations of the motor-evoked potential for understanding behaviour. Exp Brain Res 233:679-689.

Bezdudnaya T, Lane MA, Marchenko V (2018) Paced breathing and phrenic nerve responses evoked by epidural stimulation following complete high cervical spinal cord injury in rats. J Appl Physiol (1985) 125:687-696.

Bliss TV, Collingridge GL (2013) Expression of NMDA receptor-dependent LTP in the hippocampus: bridging the divide. Mol Brain 6:5.

Brown R, DiMarco AF, Hoit JD, Garshick E (2006) Respiratory dysfunction and management in spinal cord injury. Respir Care 51:853-868; discussion 869-870.

Bunge RP, Puckett WR, Hiester ED (1997) Observations on the pathology of several types of human spinal cord injury, with emphasis on the astrocyte response to penetrating injuries. Adv Neurol 72:305-315

Calvert JS, Grahn PJ, Strommen JA, Lavrov IA, Beck LA, Gill ML, Linde MB, Brown DA, Van Straaten MG, Veith DD, Lopez C, Sayenko DG, Gerasimenko YP, Edgerton VR, Zhao KD, Lee KH (2019) Electrophysiological guidance of epidural electrode array implantation over the human lumbosacral spinal cord to enable motor function after chronic paralysis. J Neurotrauma 36:14511460.

Capogrosso M, Wenger N, Raspopovic S, Musienko P, Beauparlant J, Bassi Luciani L, Courtine G, Micera S (2013) A computational model for epidural electrical stimulation of spinal sensorimotor circuits. J Neurosci 33:19326-19340.

Carter RE, Donovan WH, Halstead L, Wilkerson MA (1987) Comparative study of electrophrenic nerve stimulation and mechanical ventilatory support in traumatic spinal cord injury. Paraplegia 25:86-91.

Chandrasekaran S, Nanivadekar AC, McKernan G, Helm ER, Boninger ML, Collinger JL, Gaunt RA, Fisher LE (2020) Sensory restoration by epidural stimulation of the lateral spinal cord in upper-limb amputees. Elife 9:e54349.

Côté MP, Murray LM, Knikou M (2018) Spinal control of locomotion: individual neurons, their circuits and functions. Front Physiol 9:784.

De Vries J, De Jongste MJ, Spincemaille G, Staal MJ (2007) Spinal cord stimulation for ischemic heart disease and peripheral vascular disease. Adv Tech Stand Neurosurg 32:63-89.

DiMarco AF (2001) Neural prostheses in the respiratory system. J Rehabil Res Dev 38:601-607.

DiMarco AF (2005) Restoration of respiratory muscle function following spinal cord injury. Respir Physiol Neurobiol 147:273-287.

DiMarco AF, Kowalski KE, Geertman RT, Hromyak DR (2006) Spinal cord stimulation: a new method to produce an effective cough in patients with spinal cord injury. Am J Respir Crit Care Med 173:1386-1389.

DiMarco AF, Geertman RT, Tabbaa K, Kowalski KE (2020) Complete restoration of respiratory muscle function in subjects with spinal cord injury: interventional clinical trial. Am J Phys Med Rehabil 99: e91-e92.

Dimitrijevic MR, Dimitrijevic MM, Faganel J, Sherwood AM (1984) Suprasegmentally induced motor unit activity in paralyzed muscles of patients with established spinal cord injury. Ann Neurol 16:216-221.

Doperalski NJ, Sandhu MS, Bavis RW, Reier PJ, Fuller DD (2008) Ventilation and phrenic output following high cervical spinal hemisection in male vs. female rats. Respir Physiol Neurobiol 162:160167.

Duru PO, Tillakaratne NJK, Kim JA, Zhong H, Stauber SM, Pham TT, Xiao MS, Edgerton VR, Roy RR (2015) Spinal neuronal activation during locomotor-like activity enabled by epidural stimulation and 5-hydroxytryptamine agonists in spinal rats. J Neurosci Res 93:1229-1239.

Edgerton VR, Harkema S (2011) Epidural stimulation of the spinal cord in spinal cord injury: current status and future challenges. Expert Rev Neurother 11:1351-1353. [

Edgerton VR, Roy RR (2012) A new age for rehabilitation. Eur J Phys Rehabil Med 48:99-109.

Edgerton VR, Tillakaratne NJ, Bigbee AJ, de Leon RD, Roy RR (2004) Plasticity of the spinal neural circuitry after injury. Annu Rev Neurosci 27:145-167.

Forssberg H, Grillner S, Rossignol S (1975) Phase dependent reflex reversal during walking in chronic spinal cats. Brain Res 85:103107.

Francis JT, Gluckman BJ, Schiff SJ (2003) Sensitivity of neurons to weak electric fields. J Neurosci 23:7255-7261.

Fuller DD, Johnson SM, Olson EB, Mitchell GS (2003) Synaptic pathways to phrenic motoneurons are enhanced by chronic intermittent hypoxia after cervical spinal cord injury. J Neurosci 23:29933000.

Fuller DD, Golder FJ, Olson EB, Mitchell GS (2006) Recovery of phrenic activity and ventilation after cervical spinal hemisection in rats. J Appl Physiol (1985) 100:800-806.

Fuller DD, Doperalski NJ, Dougherty BJ, Sandhu MS, Bolser DC, Reier PJ (2008) Modest spontaneous recovery of ventilation following chronic high cervical hemisection in rats. Exp Neuro 211:97-106. 
Gad P, Choe J, Shah P, Garcia-Alias G, Rath M, Gerasimenko Y, Zhong H, Roy RR, Edgerton VR (2013) Sub-threshold spinal cord stimulation facilitates spontaneous motor activity in spinal rats. $J$ Neuroeng Rehabil 10:108.

Ganzer PD, Darrow MJ, Meyers EC, Solorzano BR, Ruiz AD, Robertson NM, Adcock KS, James JT, Jeong HS, Becker AM, Goldberg MP, Pruitt DT, Hays SA, Kilgard MP, Rennaker RL (2018) Closed-loop neuromodulation restores network connectivity and motor control after spinal cord injury. Elife 7:e32058.

Garshick E, Kelley A, Cohen SA, Garrison A, Tun CG, Gagnon D, Brown R (2005) A prospective assessment of mortality in chronic spinal cord injury. Spinal Cord 43:408-416.

Gerasimenko YP, Lavrov IA, Courtine G, Ichiyama RM, Dy CJ, Zhong H, Roy RR, Edgerton VR (2006) Spinal cord reflexes induced by epidural spinal cord stimulation in normal awake rats. J Neurosci Methods 157:253-263.

Gerasimenko YP, Lu DC, Modaber M, Zdunowski S, Gad P, Sayenko DG, Morikawa E, Haakana P, Ferguson AR, Roy RR, Edgerton VR (2015) Noninvasive reactivation of motor descending control after paralysis. J Neurotrauma 32:1968-1980.

Gill LC, Ross HH, Lee KZ, Gonzalez-Rothi EJ, Dougherty BJ, Judge AR, Fuller DD (2014) Rapid diaphragm atrophy following cervical spinal cord hemisection. Respir Physiol Neurobiol 192:66-73.

Golder FJ, Ranganathan L, Satriotomo I, Hoffman M, Lovett-Barr MR, Watters JJ, Baker-Herman TL, Mitchell GS (2008) Spinal adenosine $\mathrm{A} 2 \mathrm{a}$ receptor activation elicits long-lasting phrenic motor facilitation. J Neurosci 28:2033-2042.

Gonzalez-Rothi EJ, Streeter KA, Hanna MH, Stamas AC, Reier PJ, Baekey DM, Fuller DD (2017) High-frequency epidural stimulation across the respiratory cycle evokes phrenic short-term potentiation after incomplete cervical spinal cord injury. J Neurophysiol 118:2344-2357.

Goshgarian HG (2003) The crossed phrenic phenomenon: a model for plasticity in the respiratory pathways following spinal cord injury. J Appl Physiol (1985) 94:795-810.

Goshgarian HG (2009) The crossed phrenic phenomenon and recovery of function following spinal cord injury. Respir Physiol Neurobiol 169:85-93.

Goshgarian HG, Rafols JA (1981) The phrenic nucleus of th albino rat: a correlative HRP and Golgi study. J Comp Neurol 201:441456.

Goshgarian HG, Moran MF, Prcevski P (1986) Effect of cervical spinal cord hemisection and hemidiaphragm paralysis on arterial blood gases, $\mathrm{pH}$, and respiratory rate in the adult rat. Exp Neurol 93:440-445

Gottschall $J$ (1981) The diaphragm of the rat and its innervation. Muscle fiber composition; perikarya and axons of efferent and afferent neurons. Anat Embryol (Berl) 161:405-417.

Grahn PJ, Lavrov IA, Sayenko DG, Van Straaten MG, Gill ML, Strommen JA, Calvert JS, Drubach DI, Beck LA, Linde MB, Thoreson AR, Lopez C, Mendez AA, Gad PN, Gerasimenko YP, Edgerton VR, Zhao KD, Lee KH (2017) Enabling task-specific volitional motor functions via spinal cord neuromodulation in a human with paraplegia. Mayo Clin Proc 92:544-554.

Hall OT, McGrath RP, Peterson MD, Chadd EH, DeVivo MJ, Heinemann AW, Kalpakjian CZ (2019) The burden of traumatic spinal cord injury in the United States: disability-adjusted life years. Arch Phys Med Rehabil 100:95-100.

Harkema S, Gerasimenko Y, Hodes J, Burdick J, Angeli C, Chen Y, Ferreira C, Willhite A, Rejc E, Grossman RG, Edgerton VR (2011) Effect of epidural stimulation of the lumbosacral spinal cord on voluntary movement, standing, and assisted stepping after motor complete paraplegia: a case study. Lancet 377:1938-1947.

Hodgson JA, Roy RR, de Leon R, Dobkin B, Edgerton VR (1994) Can the mammalian lumbar spinal cord learn a motor task? Med Sci Sports Exerc 26:1491-1497.

Huie JR, Garraway SM, Baumbauer KM, Hoy KC Jr, Beas BS, Montgomery KS, Bizon JL, Grau JW (2012) Brain-derived neurotrophic factor promotes adaptive plasticity within the spinal cord and mediates the beneficial effects of controllable stimulation. Neuroscience 200:74-90.

Jackson A, Zimmermann JB (2012) Neural interfaces for the brain and spinal cord-restoring motor function. Nat Rev Neurol 8:690699.

Jackson A, Mavoori J, Fetz EE (2006a) Long-term motor cortex plasticity induced by an electronic neural implant. Nature 444:56-60.

Jackson A, Moritz CT, Mavoori J, Lucas TH, Fetz EE (2006b) The Neurochip BCl: towards a neural prosthesis for upper limb function. IEEE Trans Neural Syst Rehabil Eng 14:187-190.

Jensen VN, Alilain WJ, Crone SA (2019) Role of propriospinal neurons in control of respiratory muscles and recovery of breathing following injury. Front Syst Neurosci 13:84.

Kirkwood PA, Schmid K, Sears TA (1993) Functional identities of thoracic respiratory interneurones in the cat. J Physiol 461:667-687.

Kowalski KE, Hsieh YH, Dick TE, DiMarco AF (2013) Diaphragm activation via high frequency spinal cord stimulation in a rodent model of spinal cord injury. Exp Neurol 247:689-693.

Krause JS, Cao Y, DeVivo MJ, DiPiro ND (2016) Risk and protective factors for cause-specific mortality after spinal cord injury. Arch Phys Med Rehabil 97:1669-1678.

Lane MA (2011) Spinal respiratory motoneurons and interneurons. Respir Physiol Neurobiol 179:3-13.

Lane MA, White TE, Coutts MA, Jones AL, Sandhu MS, Bloom DC, Bolser DC, Yates BJ, Fuller DD, Reier PJ (2008) Cervical prephrenic interneurons in the normal and lesioned spinal cord of the adult rat. J Comp Neurol 511:692-709.

Lane MA, Lee KZ, Fuller DD, Reier PJ (2009) Spinal circuitry and respiratory recovery following spinal cord injury. Respir Physiol Neurobiol 169:123-132.

Lavrov I, Courtine G, Dy CJ, van den Brand R, Fong AJ, Gerasimenko Y, Zhong H, Roy RR, Edgerton VR (2008) Facilitation of stepping with epidural stimulation in spinal rats: role of sensory input. J Neurosci 28:7774-7780.

Lee KZ, Hsu SH (2017) Compensatory function of the diaphragm after high cervical hemisection in the rat. J Neurotrauma 34:26342644.

Lee KZ, Dougherty BJ, Sandhu MS, Lane MA, Reier PJ, Fuller DD (2013) Phrenic motoneuron discharge patterns following chronic cervical spinal cord injury. Exp Neurol 249:20-32.

Lee KZ, Sandhu MS, Dougherty BJ, Reier PJ, Fuller DD (2015) Hypoxia triggers short term potentiation of phrenic motoneuron discharge after chronic cervical spinal cord injury. Exp Neurol 263:314-324.

Makowski D, Ben-Shachar MS, Patil I, Lüdecke D (2020) Automated results reporting as a practical tool to improve reproducibility and methodological best practices adoption. CRAN. Available at https://github.com/easystats/report.

Malone IG, Nosacka RL, Nash MA, Otto KJ, Dale EA (2021) Electrical epidural stimulation of the cervical spinal cord: implications for spinal respiratory neuroplasticity after spinal cord injury. J Neurophysiol 126:607-626.

Mauelshagen J, Sherff CM, Carew TJ (1998) Differential induction of long-term synaptic facilitation by spaced and massed applications of serotonin at sensory neuron synapses of Aplysia californica. Learn Mem 5:246-256.

McDonald JW, Sadowsky C (2002) Spinal-cord injury. Lancet 359:417-425

McKay WB, Lim HK, Priebe MM, Stokic DS, Sherwood AM (2004) Clinical neurophysiological assessment of residual motor control in post-spinal cord injury paralysis. Neurorehabil Neural Repair 18:144-153.

McPherson JG, Miller RR, Perlmutter SI (2015) Targeted, activity-dependent spinal stimulation produces long-lasting motor recovery in chronic cervical spinal cord injury. Proc Natl Acad Sci USA 112:12193-12198.

Mendelson M (1971) Oscillator neurons in crustacean ganglia. Science 171:1170-1173.

Minassian K, McKay WB, Binder H, Hofstoetter US (2016) Targeting lumbar spinal neural circuitry by epidural stimulation to restore 
motor function after spinal cord injury. Neurotherapeutics 13:284294.

Mitchell GS, Johnson SM (2003) Neuroplasticity in respiratory motor control. J Appl Physiol (1985) 94:358-374.

Monfils MH, Teskey GC (2004) Skilled-learning-induced potentiation in rat sensorimotor cortex: a transient form of behavioural longterm potentiation. Neuroscience 125:329-336.

Moritz CT (2018) Now is the critical time for engineered neuroplasticity. Neurotherapeutics 15:628-634.

Murg M, Binder H, Dimitrijevic MR (2000) Epidural electric stimulation of posterior structures of the human lumbar spinal cord: 1. Muscle twitches - a functional method to define the site of stimulation. Spinal Cord 38:394-402.

Nair J, Streeter KA, Turner SMF, Sunshine MD, Bolser DC, Fox EJ, Davenport PW, Fuller DD (2017) Anatomy and physiology of phrenic afferent neurons. J Neurophysiol 118:2975-2990.

National Spinal Cord Injury Statistical Center (2020) Spinal cord injury facts and figures at a glance. Available at https://www. nscisc.uab.edu/Public/Facts\%20and\%20Figures\%202020.pdf.

Nishimura Y, Perlmutter SI, Eaton RW, Fetz EE (2013) Spike-timingdependent plasticity in primate corticospinal connections induced during free behavior. Neuron 80:1301-1309.

Ozen S, Sirota A, Belluscio MA, Anastassiou CA, Stark E, Koch C, Buzsáki G (2010) Transcranial electric stimulation entrains cortical neuronal populations in rats. J Neurosci 30:11476-11485.

Perim RR, Sunshine MD, Welch JF, Santiago J, Holland A, Ross A, Mitchell GS, Gonzalez-Rothi EJ (2021) Daily acute intermittent hypoxia enhances phrenic motor output and stimulus-evoked phrenic responses in rats. J Neurophysiol 126:777-790.

Radman T, Ramos RL, Brumberg JC, Bikson M (2009) Role of cortical cell type and morphology in subthreshold and suprathreshold uniform electric field stimulation in vitro. Brain Stimul 2:215-228, 228.e1-3.

Rejc E, Angeli CA (2019) Spinal cord epidural stimulation for lower limb motor function recovery in individuals with motor complete spinal cord injury. Phys Med Rehabil Clin N Am 30:337-354.

Rejc E, Angeli C, Harkema S (2015) Effects of lumbosacral spinal cord epidural stimulation for standing after chronic complete paralysis in humans. PLoS One 10:e0133998.

Romero FJ, Gambarrutta C, Garcia-Forcada A, Marín MA, Diaz de la Lastra E, Paz F, Fernandez-Dorado MT, Mazaira J (2012) Longterm evaluation of phrenic nerve pacing for respiratory failure due to high cervical spinal cord injury. Spinal Cord 50:895-898.

Sandhu MS, Dougherty BJ, Lane MA, Bolser DC, Kirkwood PA, Reier PJ, Fuller DD (2009) Respiratory recovery following high cervical hemisection. Respir Physiol Neurobiol 169:94-101.

Selverston Al, Szücs A, Huerta R, Pinto R, Reyes M (2009) Neural mechanisms underlying the generation of the lobster gastric mill motor pattern. Front Neural Circuits 3:12.

Sherwood AM, Dimitrijevic MR, Mckay WB (1992) Evidence of subclinical brain influence in clinically complete spinal-cord injury: discomplete SCI. J Neurol Sci 110:90-98.

Sherwood AM, McKay WB, Dimitrijevi? MR (1996) Motor control after spinal cord injury: assessment using surface EMG. Muscle Nerve 19:966-979.

Shupe LE, Miles FP, Jones G, Yun R, Mishler J, Rembado I, Murphy RL, Perlmutter SI, Fetz EE (2021) Neurochip3: an autonomous multichannel bidirectional brain-computer interface for closed-loop activity-dependent stimulation. Front Neurosci 15:718465.

Smith JC, Ellenberger HH, Ballanyi K, Richter DW, Feldman JL (1991) Pre-Bötzinger complex: a brainstem region that may generate respiratory rhythm in mammals. Science 254:726-729.

Streeter KA, Sunshine MD, Patel S, Gonzalez-Rothi EJ, Reier PJ, Baekey DM, Fuller DD (2017) Intermittent hypoxia enhances functional connectivity of midcervical spinal interneurons. J Neurosci 37:8349-8362.

Streeter KA, Sunshine MD, Patel SR, Gonzalez-Rothi EJ, Reier PJ, Baekey DM, Fuller DD (2020) Mid-cervical interneuron networks following high cervical spinal cord injury. Respir Physiol Neurobiol 271:103305.

Struijk JJ, Holsheimer J, Boom HB (1993) Excitation of dorsal root fibers in spinal cord stimulation: a theoretical study. IEEE Trans Biomed Eng 40:632-639.

Sunshine MD, Ganji CN, Reier PJ, Fuller DD, Moritz CT (2018) Intraspinal microstimulation for respiratory muscle activation. Exp Neurol 302:93-103.

Sunshine MD, Cassarà AM, Neufeld E, Grossman N, Mareci TH, Otto KJ, Boyden ES, Fuller DD (2021) Restoration of breathing after opioid overdose and spinal cord injury using temporal interference stimulation. Commun Biol 4:107.

Swiontek TJ, Sances A, Larson SJ, Ackmann JJ, Cusick JF, Meyer GA, Millar EA (1976) Spinal cord implant studies. IEEE Trans Biomed Eng 23:307-312.

Taccola G, Sayenko D, Gad P, Gerasimenko Y, Edgerton VR (2018) And yet it moves: recovery of volitional control after spinal cord injury. Prog Neurobiol 160:64-81.

Tator CH, Minassian K, Mushahwar VK (2012) Spinal cord stimulation: therapeutic benefits and movement generation after spinal cord injury. Handb Clin Neurol 109:283-296.

Tawfik VL, Chang S-Y, Hitti FL, Roberts DW, Leiter JC, Jovanovic S, Lee KH (2010) Deep brain stimulation results in local glutamate and adenosine release: investigation into the role of astrocytes. Neurosurgery 67:367-375.

Van Buyten JP, Smet I, Liem L, Russo M, Huygen F (2015) Stimulation of dorsal root ganglia for the management of complex regional pain syndrome: a prospective case series. Pain Pract 15:208-216.

Vinit S, Gauthier P, Stamegna JC, Kastner A (2006) High cervical lateral spinal cord injury results in long-term ipsilateral hemidiaphragm paralysis. J Neurotrauma 23:1137-1146.

Waddimba AC, Jain NB, Stolzmann K, Gagnon DR, Burgess JF, Kazis LE, Garshick E (2009) Predictors of cardiopulmonary hospitalization in chronic spinal cord injury. Arch Phys Med Rehabil 90:193-200.

Wagner FB, Mignardot JB, Le Goff-Mignardot CG, Demesmaeker R, Komi S, Capogrosso M, Rowald A, Seáñez I, Caban M, Pirondini E, Vat M, McCracken LA, Heimgartner R, Fodor I, Watrin A, Seguin P, Paoles E, Van Den Keybus K, Eberle G, Schurch B, et al. (2018) Targeted neurotechnology restores walking in humans with spinal cord injury. Nature 563:65-71.

Wenjin W, Wenchao L, Hao Z, Feng L, Yan W, Wodong S, Xianqun F, Wenlong D (2011) Electrical stimulation promotes BDNF expression in spinal cord neurons through $\mathrm{Ca}(2+)$ - and Erk-dependent signaling pathways. Cell Mol Neurobiol 31:459-467.

Wilks SJ, Richner TJ, Brodnick SK, Kipke DR, Williams JC, Otto KJ (2012) Voltage biasing, cyclic voltammetry, and electrical impedance spectroscopy for neural interfaces. J Vis Exp (60):3566.

Williams JC, Hippensteel JA, Dilgen J, Shain W, Kipke DR (2007) Complex impedance spectroscopy for monitoring tissue responses to inserted neural implants. J Neural Eng 4:410-423.

Zanos S, Richardson AG, Shupe L, Miles FP, Fetz EE (2011) The Neurochip-2: an autonomous head-fixed computer for recording and stimulating in freely behaving monkeys. IEEE Trans Neural Syst Rehabil Eng 19:427-435.

Zholudeva LV, Qiang L, Marchenko V, Dougherty KJ, SakiyamaElbert SE, Lane MA (2018) The neuroplastic and therapeutic potential of spinal interneurons in the injured spinal cord. Trends Neurosci 41:625-639. 